\title{
Enhanced photocatalytic reduction of carbon dioxide in optical fiber monolith reactor with transparent glass balls
}

Huiyao Chen ${ }^{1}$, Fengming $\mathrm{Chu}^{1}$, Lijun Yang ${ }^{1 *}$, Oluwafunmilola Ola ${ }^{2 *}$, Xiaoze $\mathrm{Du}^{1}$, Yongping

Yang $^{1}$

1. Key Laboratory of Condition Monitoring and Control for Power Plant Equipment of Ministry of

Education

School of Energy Power and Mechanical Engineering, North China Electric Power University,

Beijing 102206, China

2. College of Engineering, Mathematics and Physical Sciences, University of Exeter, Exeter, EX4

4QF, United Kingdom

\section{Abstract}

Photocatalytic reduction of carbon dioxide to produce methanol is a promising approach to restrain greenhouse gases emissions and mitigate energy shortage, which attracts extensive concerns in recent years. The optical fiber monolith reactor with solid glass balls for photocatalytic carbon dioxide reduction is proposed in this work to increase the product concentration, and the glass balls are transparent and coated with photocatalysts evenly to absorb light. The photocatalytic reduction of carbon dioxide in optical fiber monolith reactor is numerically investigated, by which the effects of glass ball number, location, circle and layer on the production are analyzed. The results show that in the single-circle and single-layer model, the outlet methanol concentration

\footnotetext{
* Corresponding author: Lijun Yang. Tel: +86(10)61773373; Fax: +86(10)61773877.

Email address: yanglj@ncepu.edu.cn

Oluwafunmilola Ola. Tel: +44 (0) 139272 5492. E-mail address: O.Ola@exeter.ac.uk
} 
increases with increasing the ball number. The closer to the fiber and reactor inlet the balls keep, the higher the methanol production is. As the circle and layer numbers increase, the methanol concentration also increases. The outlet methanol average concentration of the optical fiber monolith reactor with 3-circle and 5-layer balls gets $11.43 \%$ higher than the case without glass balls.

Key words: Photocatalytic; Carbon dioxide reduction; Methanol production; Optical fiber monolith reactor; Glass balls 
-Nomenclature

C

$d$

D

$f_{\theta}$

I

$k$

K

$l$

$L$

M

$n$

$p$

$P$

$r$

$R$

$T$

$u$

V

$z$

Greek letters

$\alpha$ concentration, $\mathrm{mol} \mathrm{m} \mathrm{m}^{-3}$

diameter, $\mathrm{m}$

diffusion coefficient, $\mathrm{m}^{2} \mathrm{~s}^{-1}$

fraction of incident light with incident angle less than $90^{\circ}$

light intensity, $\mathrm{W} \mathrm{m}^{-2}$

kinetic rate constant, $\mathrm{m}^{4} \mathrm{~s}^{-1} \mathrm{~mol}^{-2}$

adsorption equilibrium constant

distance, $\mathrm{mm}$

reactor length, $\mathrm{mm}$

relative molecular mass

number

pressure, $\mathrm{Pa}$

total pressure, $\mathrm{Pa}$

reaction rate, $\mathrm{mol} \mathrm{m}^{-3} \mathrm{~s}^{-1}$

radius, $\mathrm{mm}$

temperature, $\mathrm{K}$

velocity, $\mathrm{m} \mathrm{s}^{-1}$

molar volume, $\mathrm{cm}^{3} \mathrm{~mol}^{-1}$

axial position, $\mathrm{mm}$

refractive loss coefficient, $\mathrm{cm}^{-1}$ 
$\sigma$

$\lambda$

$\phi$

Subscript and superscript

f

fc

1

$\mathrm{m}$

mc

gs

gsc

W

r

$\theta$ attenuation coefficient of the tip light flux, $\mathrm{cm}^{-1}$

catalyst film thickness, nm

local attenuation coefficient of catalyst thin-film, $\mathrm{cm}^{-1}$

energy conversion efficiency

molecular weight of gas

viscosity, $\mathrm{m}^{2} \mathrm{~s}^{-1}$

density, $\mathrm{kg} \mathrm{m}^{-3}$

circumferential coordinate, rad

fractional surface coverage

overall factor

quantum efficiency 


\section{Introduction}

The continuous development of world economy and progress of human civilization since the industrial revolution of mankind basically depend on the adequate energy supply, generally fossil fuels [1]. However, the non-renewable characteristics of fossil fuels compel human explore the renewable sources aiming at sustainable development [2]. Besides, the carbon flow between the ocean and the atmosphere should be natural while human activity adds too much $\mathrm{CO}_{2}$ to that cycle [3]. Typically, the burning of fossil fuels produces a large amount of greenhouse gases, mainly carbon dioxide [4], resulting in many environmental issues such as global warming [5]. Therefore, the great challenge for the mankind is to take powerful measures to develop alternative renewable energy resources [6] and reduce atmospheric $\mathrm{CO}_{2}$ concentrations [7]. Among various $\mathrm{CO}_{2}$ capture technologies [8], it seems practical and alternative to take advantage of the MEA (monoethanolamine) and ammonia aqueous solution absorption in packed absorbing columns [9, 10] or bubble columns [11], hydrate-based biogas upgrading with $\mathrm{CO}_{2}$ valorization [12] and artificial photosynthesis in photoreactors [13], etc. Besides, using coal fly ash is an available and potential way to store carbon dioxide [14], and the conversion to fuels as well as the utilization of $\mathrm{CO}_{2}$ also attracts extensive attention [15]. It is potential that methanol synthesis using captured $\mathrm{CO}_{2}$ could reduce $\mathrm{CO}_{2}$ emission and produce the clean fuel [16]. With the efforts of many scholars, the technologies of photocatalytic reduction of $\mathrm{CO}_{2}$ have made great progress [17], among which the $\mathrm{CO}_{2}$ photo-hydrogenation by mimicking photosynthesis is one of the best routes of obtaining renewable hydrocarbon fuels under 
the sunlight and action of photocatalyst in photoreactors [3]. This method is effective to reduce the atmospheric $\mathrm{CO}_{2}$ concentration and relieve global energy shortage [18]. However, the hydrocarbon yield is commonly low [19] due to the limited reaction surface area, so many researchers aim at improving the photoreactor structure to promote the $\mathrm{CO}_{2}$ reduction [20] and hydrocarbon conversion [21].

In previous studies, various photoreactors such as slurry reactor, fixed bed reactor, surface coated reactor, twin reactor [22], optical fiber photocatalytic reactor [23], annular and bubble flow reactors [24] were proposed, for which the structures play an important role in the $\mathrm{CO}_{2}$ photoreaction. For optical fiber monolith reactor (OFMR), the optical fiber is inserted into the parallel reaction channels, and the catalyst is coated on the fiber and monolith surfaces to convert the $\mathrm{CO}_{2}$ to methanol under the artificial light $[25,26]$. This type of photoreactor shows many advantages over other photoreactors [27], such as the efficient and uniform light distribution, good interaction between the catalyst layer and photons, high conversion efficiency and product yield, low pressure drop and operational costs [28], so it seems more promising for the photocatalytic $\mathrm{CO}_{2}$ reduction [29].

For the OFMR, the solar energy utilization ratio for the $\mathrm{CO}_{2}$ photoreduction is only around 3\% and the reaction surface area is not large enough, which shows a wide space to increase the solar energy conversion efficiency and improve the photocatalytic $\mathrm{CO}_{2}$ reduction [20]. In the aforementioned studies, more emphases were placed upon the energy conversion efficiency and modified effective photocatalysts, while the photoreactor structure is still worthy of further investigation [23]. 
As a credible way of OFMR, a bundle of optical fibers like honeycomb is commonly used to transmit the light with solar concentrating devices and increase the reaction surface area. In this work, a filling transparent solid glass ball model is proposed in the light of OFMR, where the surfaces of the fiber, monolith, and the glass balls are all coated with photocatalysts to adequately absorb photons for the photocatalytic $\mathrm{CO}_{2}$ reduction and improve the energy conversion efficiency. By this way, the photoreaction surface area is enlarged without destroying the central symmetric structure of the reactor and the disturbance to the flow is minimized as much as possible. The filling ball model is simulated in this paper using the commercial multiphysics software COMSOL. The numerical simulation can not only verify the reliability and accuracy of the experimental results after the experiments, but also predict the feasibility before the experiments. The yield and the average outlet concentration of the product, the $\mathrm{CO}_{2}$ concentration and velocity distribution, are all obtained and compared with the photoreaction in the traditional OFMR, which can contribute to the optimal design and energy efficient operation of photocatalytic $\mathrm{CO}_{2}$ reduction in optical fiber monolith reactor.

\section{Multi-physics modeling}

Due to the identity of each flow-path, only one reactor unit, namely one channel, is taken into account in this work. The comprehensive and rigorous model is developed, which consists of three computational modules of chemistry, transport of dilute species and creeping flow.

2.1. Physical model 
The traditional and proposed models are schematically shown in Fig. 1. In the traditional model, the light source is set at the inlet of channel and perpendicular to the entrance section as shown in Fig. 1(a) [28, 30], with the light intensity kept constant in the experiment. Based on previous studies, the reverse arrangement of the light source is more favorable to the photoreaction [20], so the light source is set at the outlet to emit ultraviolet light in the proposed model, as shown in Fig. 1(b). 15 same transparent solid glass balls coated with photocatalyst layers are placed outside the fiber in the flow-path, increasing the photoreaction surface area in the single channel. The fiber made of quartz glass is set in the center of the channel as a light conductor, labeled as 1, and the quartz glass is assumed to be hyaline to ultraviolet light [31]. The monolith is composed of opaque ceramics, labeled as 2 and the glass balls are labeled as 3 . The photocatalyst, consisting of $\mathrm{TiO}_{2}$ containing $1 \% \mathrm{NiO} / \mathrm{InTaO}_{4}(\mathrm{sg})$, is evenly coated on three surfaces [31]. The reactants of $\mathrm{CO}_{2}$ and $\mathrm{H}_{2} \mathrm{O}$ flow into the channel from the inlet and react in the photoreactor, and the products leave out at the outlet.

The location of the balls in the photoreactor is shown in Fig. 2. Based on the structure of the proposed model, the following assumptions are taken to simplify the model without adhibiting large deviation in numerical simulations:

(1) The glass balls are well-distributed outside the fiber in the same plane with $z$ equal to $z_{g s}$. The angle between two adjacent balls is $\theta$ and the distance from each ball center to fiber center is labeled as $r_{g s}$, as shown in Fig. 2.

(2) The reaction system maintains a constant temperature of $298 \mathrm{~K}$ at which the Arrhenius expression is negligible [28]. 
(3) In the channel, all the species are homogeneous, incompressible and isotropic Newtonian fluids.

(4) The flow inside the channel is steady, laminar and fully developed, with no backward flow.

(5) All the transparent glass balls are exactly the same, with the volume and radius of $0.01 \mathrm{~mm}^{3}$ and $0.13365 \mathrm{~mm}$, respectively. The transmissivity of the glass ball is 1 , which means the light is only absorbed by the thin-film photocatalyst and the unabsorbed light passes through the glass balls directly without any loss.

(6) Each glass ball is sustained and fixed with a silex glass scaffold on the fiber. The scaffold is extremely fine to avoid disturbing the fluid flows in the channel. Silex glass is transparent to UV light, not preventing the light transmission. Moreover, silex glass is steady and chemically inert, not reacting with various constituents of the fluids. So the scaffolds are ignored in the simulation.

(7) Photocatalytic reaction of carbon dioxide on the photocatalyst film can be described as follows.

$$
\mathrm{CO}_{2}+2 \mathrm{H}_{2} \mathrm{O} \stackrel{\text { photocatalyst }}{h v} \mathrm{CH}_{3} \mathrm{OH}+\frac{3}{2} \mathrm{O}_{2}
$$

It does not focus on the photoreaction mechanism, but the variations of the reactants and products.

\subsection{Fluid flow model}

For the incompressible viscous fluid flows of $\mathrm{CO}_{2}$ and $\mathrm{H}_{2} \mathrm{O}$, the Navier-Stokes equation in the columnar coordinate system is adopted with the following form:

$$
\frac{\partial u_{r}}{\partial r}+\frac{1}{r} \frac{\partial u_{\theta}}{\partial \theta}+\frac{\partial u_{z}}{\partial z}=0
$$




$$
\begin{aligned}
& u_{r} \frac{\partial u_{r}}{\partial r}-\frac{u_{\theta}^{2}}{r}+\frac{u_{\theta}}{r} \frac{\partial u_{r}}{\partial \theta}+u_{z} \frac{\partial u_{r}}{\partial z} \\
& =-\frac{1}{\rho} \frac{\partial p}{\partial r}+v\left(\frac{\partial^{2} u_{r}}{\partial r^{2}}+\frac{1}{r} \frac{\partial u_{r}}{\partial r}-\frac{u_{r}}{r^{2}}-\frac{2}{r^{2}} \frac{\partial u_{\theta}}{\partial \theta}+\frac{1}{r^{2}} \frac{\partial^{2} u_{r}}{\partial \theta^{2}}+\frac{\partial^{2} u_{r}}{\partial z^{2}}\right) \\
& u_{r} \frac{\partial u_{\theta}}{\partial r}+\frac{u_{r} u_{\theta}}{r}+\frac{u_{\theta}}{r} \frac{\partial u_{\theta}}{\partial \theta}+u_{z} \frac{\partial u_{\theta}}{\partial z} \\
& =-\frac{1}{\rho r} \frac{\partial p}{\partial \theta}+v\left(\frac{\partial^{2} u_{\theta}}{\partial r^{2}}+\frac{1}{r} \frac{\partial u_{\theta}}{\partial r}-\frac{u_{\theta}}{r^{2}}+\frac{2}{r^{2}} \frac{\partial u_{r}}{\partial \theta}+\frac{1}{r^{2}} \frac{\partial^{2} u_{\theta}}{\partial \theta^{2}}+\frac{\partial^{2} u_{\theta}}{\partial z^{2}}\right) \\
& u_{r} \frac{\partial u_{z}}{\partial r}+\frac{u_{\theta}}{r} \frac{\partial u_{z}}{\partial \theta}+u_{z} \frac{\partial u_{z}}{\partial z}=-\frac{1}{\rho} \frac{\partial p}{\partial z}+v\left(\frac{\partial^{2} u_{z}}{\partial r^{2}}+\frac{1}{r} \frac{\partial u_{z}}{\partial r}+\frac{1}{r^{2}} \frac{\partial^{2} u_{z}}{\partial \theta^{2}}+\frac{\partial^{2} u_{z}}{\partial z^{2}}\right)(5)
\end{aligned}
$$

where $u_{r}, u_{\theta}, u_{z}$ are the velocities in the $r, \theta, z$ directions. $p$ is the pressure. $\rho$ and $v$ are the density and viscosity. The corresponding boundary conditions satisfy:

$$
\begin{aligned}
& u_{r}=u_{\theta}=0, u_{z}=u_{\text {inlet }} \quad z=0 \\
& u_{r}=u_{\theta}=0, \frac{\partial u_{z}}{\partial z}=0 \quad z=L \\
& u_{r}=u_{\theta}=u_{z}=0 \text { Other boundaries }
\end{aligned}
$$

For the reactant gases, marked $A$ and $B$, the diffusion coefficient $D$ can be obtained from the following semi-empirical formula [32]:

$$
D=\frac{435.7 T^{3 / 2}}{P\left(V_{A}^{1 / 3}+V_{B}^{1 / 3}\right)^{2}} \sqrt{\frac{1}{M_{A}}+\frac{1}{M_{B}}}
$$

Where $T$ is the actual temperature, $P$ is the total pressure and $M$ is the molecular mass

of the gas. $V$ is the molar volume with the constant of $22.4 \times 10^{3} \mathrm{~cm}^{3} \cdot \mathrm{mol}^{-1}$. Comparing with $\mathrm{CO}_{2}$, the diffusion coefficients of $\mathrm{H}_{2} \mathrm{O}, \mathrm{CH}_{3} \mathrm{OH}$ and $\mathrm{O}_{2}$ can be obtained by Eq. (9).

\subsection{Reaction kinetics model}

During the photocatalytic $\mathrm{CO}_{2}$ reduction, the reaction rate is proportional to the absorption of the reactants with different adsorption coefficients, and the product is desorbed from the surface of photocatalyst film. The reaction kinetic equation in the 
present work is developed based upon the following two aspects:

(1) Langmui-Hinshelwood equation is used to fit the photocatalytic reduction rate of $\mathrm{CO}_{2}$ with the reaction rate expressed as [33]:

$$
r=k \sigma_{A} \sigma_{B}=k \frac{K_{A} p_{A} K_{B} p_{B}}{\left(1+K_{A} p_{A}+K_{B} p_{B}\right)^{2}}
$$

where $\sigma$ is the surface coverage ratio of reactants; $k$ is the kinetic rate constant; $K$ is adsorption equilibrium constant; $p$ is the partial pressure of each reagent in the mixture. $k$ and $K$ are both related to the actual temperature.

(2) A power law relation is applied between the total absorbed radiation on photocatalyst films and the kinetic rate constant.

It should be noted that the detachment of the products from photocatalyst film is incomplete, so the reaction active region is covered and the efficiency of photocatalytic reduction of $\mathrm{CO}_{2}$ is reduced. Furthermore, the reverse reaction may occur to some extent, and part of the resultant methanol is oxidized to $\mathrm{CO}_{2}$ by oxygen. Therefore, the double effects of photocatalytic reduction and oxidation are both taken into account and the reactants and resultants are supposed to be adsorbed in the same catalyst activity region. Eq. (10) can be modified as the following form [34]:

$$
r=k I^{n} \frac{K_{A} p_{A} K_{B} p_{B}}{\left(1+K_{A} p_{A}+K_{B} p_{B}+K_{C} p_{C}+K_{D} p_{D}\right)^{2}}
$$

where $I$ represents the incident ultraviolet light intensity; $n$ is the power-law coefficient, changing from 0.5 to 1 , to describe the reaction rate on account of light intensity. The larger the $n$ value of the photoreactor, the more effective the photocatalytst thin-film sucks up the incident photons [35]. 
Combining the Eq. (1) and Eq. (11), the kinetic formula follows:

$$
r=k I^{n} \frac{K_{\mathrm{H}_{2} \mathrm{O}} K_{\mathrm{CO}_{2}}\left(p_{\mathrm{H}_{2} \mathrm{O}} p_{\mathrm{CO}_{2}}\right)}{\left(1+K_{\mathrm{H}_{2} \mathrm{O}} p_{\mathrm{H}_{2} \mathrm{O}}+K_{\mathrm{CO}_{2}} p_{\mathrm{CO}_{2}}+K_{\mathrm{O}_{2}} p_{\mathrm{O}_{2}}+K_{\mathrm{CH}_{3} \mathrm{OH}} p_{\mathrm{CH}_{3} \mathrm{OH}}\right)^{2}}
$$

In order to reduce the calculation errors for the photocatalytic $\mathrm{CO}_{2}$ reduction, three assumptions are made: (a) the dynamic reaction rate and the coverage area of $\mathrm{CO}_{2}$ are in the direct ratio; (b) the main adsorbent in the photocatalyst film is $\mathrm{CO}_{2}$ and methanol; (c) the photons arriving at the catalyst coating are entirely taken in, namely the value of $n$ is 1 . Therefore, the Eq. (12) is simplified [35]:

$$
r=k I \frac{K_{\mathrm{H}_{2} \mathrm{O}} K_{\mathrm{CO}_{2}}\left(p_{\mathrm{H}_{2} \mathrm{O}} p_{\mathrm{CO}_{2}}\right)}{\left(1+K_{\mathrm{CO}_{2}} p_{\mathrm{CO}_{2}}+K_{\mathrm{CH}_{3} \mathrm{OH}} p_{\mathrm{CH}_{3} \mathrm{OH}}\right)^{2}}
$$

\subsection{Light intensity distribution model}

Marinangeli and Ollis [36] put forward a simple exponential decay equation to characterize the distribution of light intensity in an optical fiber coated with a photocatalyst thin-film, as follows:

$$
I_{\text {axial }}(z)=\exp (-\alpha z) I_{\text {input }}
$$

where $I_{\text {axial }}(\mathrm{z})$ represents the axial light intensity of the optical fiber along the $z$-axis; $I_{\text {input }}$ refers to the light intensity at the entrance of the optical fiber with the $z$ value of 0 . $\alpha$ is the refraction loss coefficient gained from the fitting experimental data. However, some other parameters such as the wavelength, refractivity, angle of incidence, catalyst layer thickness, the coating porosity and the length of the fiber also affect the light transfer efficiency (or called diopter) in the photocatalyst thin-film of OFMR [37]. As a result, a new parameter $f_{\theta}$ is introduced to make the equation more reliable [38]:

$$
I_{\text {axial }}(z)=\left[\left(1-f_{\theta}\right)+f_{\theta} \exp (-\alpha z)\right] I_{\text {input }}
$$


$f_{\theta}$ is the percentage of the incident light with the incident angle of less than 90 degrees in total incident light. The fraction $I_{\text {input }}\left(1-f_{\theta}\right)$ indicates the light passing through the entire fiber without being absorbed by the photocatalyst film, with the incident direction approximately parallel with the flow channel surface. The greater the $f_{\theta}$ is, the less the ray of light almost parallel to the $z$-axis is, thereby more difficult to refract from the fiber to the catalyst coating surface. Subsequently, Lin and Valsaraj [26] got success in modeling and measuring the light intensity distribution of every single element in OFMR, based on which the refractive light intensity passing through the photocatalyst film on the fiber decreases by orders of magnitude, but increases clearly at the back of the fiber. Thus, the equation takes the following form:

$$
I_{f}=\frac{1}{4} d_{f}\left\{\alpha f_{\theta} \exp [-(\alpha z+\varepsilon \delta)] I_{\text {input }}+\beta \exp [-\beta(L-z)] I_{\text {output }}\right\}
$$

where $\beta$ refers to the attenuation coefficient of the top light intensity; $\varepsilon$ represents the local attenuation coefficient of the catalyst thin-film, depending on the physical characteristics of the film. $\beta, \alpha, \varepsilon$ and $f_{\theta}$ are all obtained from the experimental data. Besides, $I_{\text {output }}$ is the light intensity at the end of the fiber with $z$ equal to $L$, as follows.

$$
I_{\text {output }}(L)=\left[\left(1-f_{\theta}\right)+f_{\theta} \exp (-\alpha L)\right] I_{\text {input }}
$$

So the energy conversion efficiency $\eta$ can be calculated by the following formula.

$$
\eta=f_{\theta}(1-\exp (-\alpha L))
$$

In this simulation, it is assumed that the number of photons participating in the photoreaction is constant and the energy conversion efficiency keeps fixed, with the value of $0.294 \%$. The emphases of this research are placed on the improved photoreactor structures to achieve a high product concentration. Besides, in previous 
studies, the distribution of ultraviolet transmission light crossing the catalyst coating of the fiber to the honeycomb channel is called Linear Source Spherical Emission, namely LSSE [39]. Hence, the relation between the ultraviolet light intensity and two different coating surfaces satisfies:

$$
I_{m c}=\frac{R_{f}}{R_{m}} I_{f c}(z)
$$

where $I_{m c}$ and $I_{f c}$ are the light intensity on the catalyst coating of the monolith and the fiber respectively. $R_{f}$ is the fiber radius; $R_{m}$ is the average distance between the $z$-axis and the monolith.

\subsection{Multi-physical model parameters}

The variables and parameters in the photocatalytic $\mathrm{CO}_{2}$ reduction system can be divided into seven categories, as shown in Table 1. The fundamental structure of the proposed model in this work is same as Wang's model [31], except the bigger reaction surface area from the additional transparent glass balls with photocatalyst coating. The flow channel near the balls gets narrowed, which obstruct the fluid flows. The geometric parameters are obtained from the specific size of the true OFMR. The hydrodynamic and mass transfer parameters are calculated by the aforementioned equations, and the radiation parameters are obtained by literature [27]. The $\mathrm{CO}_{2}$ acts as the primary reactant while water vapor as the pivotal factor affecting the photoreaction rate. From the experiment data, the inlet concentrations of $\mathrm{CO}_{2}$ and $\mathrm{H}_{2} \mathrm{O}$ are estimated as $98 \%$ and $2 \%$, that is, pure $\mathrm{CO}_{2}$ with saturated water vapor [28].

\subsection{Validation of numerical results}

The proposed model of optical fiber monolith reactor with glass balls is developed 
from the previous model without glass balls, which has been studied by Liou et al. [28], Lin and Valsaraj [26]. For the traditional optical fiber monolith reactor without glass balls, the effects of fiber position and operating parameters on the photocatalytic $\mathrm{CO}_{2}$ reduction have been investigated by using CFD method in our previous work [29], which are in good agreements with the experimental data of Liou et al. [28]. It shows that the multi-physics modeling and computational methods are reliable enough to further study the optimized structure of the photoreactor with transparent glass balls in this work.

\section{Results and discussion}

The variations of product concentration, reaction rate and fluid velocity are presented to explain the photocatalytic $\mathrm{CO}_{2}$ reduction characteristics in optical fiber monolith reactor with glass balls. The effects of the ball number and location, circle and layer numbers are discussed.

\subsection{Variable fields}

As an illustrative case, the proposed model with 15 glass balls coated with photocatalyst is analyzed, and the volume of each glass ball is $0.01 \mathrm{~mm}^{3}$.

The $\mathrm{CH}_{3} \mathrm{OH}$ concentration and reaction rate along the $z$-axis in the proposed model are shown in Fig. 3. It can be seen that the methanol concentration increases along the $z$-axis while the reaction rate decreases clearly on the contrary. Because the reactants flow into the reactor from the inlet and then react accompanying with the flow, the reactant concentrations near the entrance are high and becomes lower in the process of flow, so the reaction rate decreases gradually along the flow channel. 
Considering the symmetric structure of OFMR, the methanol concentration distributions in two models are shown in Fig. 4, where the product concentration increases clearly in the flow direction. Moreover, the concentration distribution of the proposed model is almost similar to that of the traditional one, while the average outlet $\mathrm{CH}_{3} \mathrm{OH}$ concentration in the proposed model is higher due to the increased reaction surface from the balls coated with photocatalyst. For better displaying the changing trends, Fig. 5 shows the average $\mathrm{CH}_{3} \mathrm{OH}$ concentration along the $z$-axis in the traditional and proposed models. When $z$ equals $5 \mathrm{~mm}$, the average concentration of $\mathrm{CH}_{3} \mathrm{OH}$ for the proposed model is $9.707 \mathrm{e}-6 \mathrm{~mol} / \mathrm{m}^{3}$, increases by $1.02 \%$ compared with the traditional model with the $\mathrm{CH}_{3} \mathrm{OH}$ concentration of $9.6081 \mathrm{e}-6 \mathrm{~mol} / \mathrm{m}^{3}$. While at the outlet, the $\mathrm{CH}_{3} \mathrm{OH}$ concentration increases by $0.8 \%$. Due to the reduced reaction rate along the $z$-axis, the methanol concentration increases slowly and arrives at the maximum at the outlet of the photoreactor. As seen from the results, it is feasible to promote the $\mathrm{CH}_{3} \mathrm{OH}$ yield by adding the transparent balls coated with photocatalysts into the OFMR. However, the increase of the $\mathrm{CH}_{3} \mathrm{OH}$ yield is still of limited, so the emphases are place upon the photoreactor structure improvement by adding transparent balls in the following research.

The fluid velocity in the photoreactor is shown in Fig. 6. It can be observed that the velocities near the fiber, monolith and balls are small due to the near-wall effect. Compared with the traditional model without balls shown in Fig. 6(a), the maximum local velocity becomes bigger and the minimum local velocity is smaller at the ball center plane where the flow channel gets narrow due to the disturbance of the glass 
balls to some extent, as shown in Fig. 6(b).

\subsection{Effects of ball number}

Based on the fixed volume of each ball, the effects of ball number on the photocatalytic $\mathrm{CO}_{2}$ reduction are investigated. For the traditional model, the calculated outlet methanol concentration is $1.2664 \mathrm{e}-5 \mathrm{~mol} / \mathrm{m}^{3}$. Keeping other parameters same as the traditional model, the proposed model with different ball numbers at one layer and one circle, as shown in Fig. 7, is simulated. During the simulation, the balls with the same axial coordinate, $z_{\mathrm{gs}}$, distribute uniformly around the fiber. Moreover, the effect of $z_{\mathrm{gs}}$ is also studied. The outlet average methanol concentrations at different ball numbers and axial coordinate $z_{\mathrm{gs}}$ are shown in Fig. 8. It can be observed that the outlet methanol concentration increases with increasing the ball number, because the balls coated with photocatalyst lead to the increased reaction surface, thus a high product concentration. The outlet $\mathrm{CH}_{3} \mathrm{OH}$ concentration rises firstly and decreases later as the $z_{g s}$ increases. For the current geometric structure, the model with 15 balls at one layer and one circle is preferred when the $r_{g s}$ equals $0.65 \mathrm{~mm}$.

\subsection{Effects of ball location}

The influences of ball location on the outlet $\mathrm{CH}_{3} \mathrm{OH}$ average concentration in different models are studied, where the ball location is defined by the radial coordinate and axial coordinate, $r_{g s}$ and $z_{g s}$ as shown in Fig. 2. Fig. 9 shows the outlet $\mathrm{CH}_{3} \mathrm{OH}$ average concentrations at various $z_{g s}$ and $r_{g s}$. When the $z_{g s}$ is constant, the product concentration decreases clearly with the increase of $r_{g s}$. The smaller the $r_{g s}$ is, the closer to the fiber the glass balls are and the more photons the photocatalysts coated on the 
glass balls could receive. Therefore, the concentration of $\mathrm{CH}_{3} \mathrm{OH}$ gets lower along with the $r_{g s}$. When the $z_{g s}$ is bigger than $0.5 \mathrm{~mm}$, the changing trends of $\mathrm{CH}_{3} \mathrm{OH}$ average concentration are similar, that is, it decreases with increasing the $z_{g s}$, as shown in Fig. 9(b). The reaction rate decreases as the axial coordinate ( $z$ value) increases, so when the balls are close to the inlet, the reaction rate is big and the yield of the products is relatively large. When the $z_{g s}$ arrives at $3 \mathrm{~mm}$, the proposed photoreactor with balls fails in increasing the production, and the outlet $\mathrm{CH}_{3} \mathrm{OH}$ concentration is even lower than the traditional model. However, when the balls are close to the inlet with $z_{g s}$ equal to $0.2 \mathrm{~mm}, 0.3 \mathrm{~mm}, 0.4 \mathrm{~mm}$, the outlet $\mathrm{CH}_{3} \mathrm{OH}$ concentrations differ widely from other cases. Although the reaction rate is bigger near the inlet, the disturbance of the balls in the flow-path results in an unfavorable effect on the photoreaction, as shown in Fig. 9(a). As a result, a relatively optimum methanol production of about $1.2764 \mathrm{e}-5 \mathrm{~mol} / \mathrm{m}^{3}$ is reached when the $r_{g s}$ equals $0.69 \mathrm{~mm}$ and $z$ equals $0.4 \mathrm{~mm}$.

\subsection{Effects of layer number}

In the single-layer model as discussed above, the production decreases with increasing the axial distance, so the multi-layer balls set at the inlet are recommended. By increasing the ball layer along the axial direction, the photocatalytic $\mathrm{CO}_{2}$ reduction in optical fiber monolith reactor is numerically investigated. Fig. 10 shows the proposed models with multi-layer balls, which can be regarded as a superposition of some singlelayer balls at different axial locations. For the first layer closest to the inlet, the axial coordinate $z_{g s}$ is set $0.2 \mathrm{~mm}$. Subsequently, the ball layer increases and the distance between two adjacent layers is $0.3 \mathrm{~mm}$. For each layer, a relatively optimum radial 
location is set on account of previous calculation results shown in Fig. 9. When the axial coordinate of balls $\left(z_{\mathrm{gs}}\right)$ equals $0.2 \mathrm{~mm}$, the optimum radial location is $0.9 \mathrm{~mm}$. If $z_{g s}$ is greater than $0.4 \mathrm{~mm}$, the relatively better radial location for the balls is the same, namely $r_{g s}$ equals $0.65 \mathrm{~mm}$.

For the multi-layer balls, the outlet average methanol concentration is shown in Fig. 11. As the layer number $n_{l}$ increases, the product yield first increases and then decreases. The optimal layer number is 8 , at which the product concentration reaches the peak value of $1.2990 \mathrm{e}-5 \mathrm{~mol} / \mathrm{m}^{3}$. In general, as the ball layer increases, the surface area for photocatalytic $\mathrm{CO}_{2}$ reduction will increase because the balls are coated with photocatalyst evenly. But the disturbance of the balls on the flow also becomes strong, and the promoting effect on the methanol formation gets weak when the balls are far away from the inlet. As a result, there must exist an optimum layer number for the model of multi-layer balls.

\subsection{Effects of circle number}

Besides the multi-layer configuration, increasing the ball circle is another method to improve photocatalytic $\mathrm{CO}_{2}$ reduction in optical fiber monolith reactor. Based on one layer model, the model with multi-circle balls is developed. As aforementioned, more ball number in one circle is of benefit to the outlet methanol concentration. The multicircle balls model can also be regarded as a superposition of the single-circle model. Due to the fixed ball volume and the limitation of channel space, only 3 circles are set in the flow-path, as shown in Fig. 12. The circle closest to the fiber is defined as circle $\mathrm{a}$, the middle circle is circle $\mathrm{b}$ and the circle closest to the monolith is circle $\mathrm{c}$. The 
numbers of balls in circle a, b, c are 15, 20, 24 and the radial distances are $0.65 \mathrm{~mm}$, $0.93 \mathrm{~mm}, 1.21 \mathrm{~mm}$, respectively.

The variation of outlet $\mathrm{CH}_{3} \mathrm{OH}$ concentration with the axial location for multicircle model is shown in Fig. 13. It can be seen that the $\mathrm{CH}_{3} \mathrm{OH}$ production rises with increasing the circle number thanks to the increased reaction surface area from more circles of balls with photocatalyst films. For the fixed circle, the production decreases as the ball axial location increases, which is similar to the results of one layer and one circle model. As the aforementioned results, the reaction rate decreases with increasing the axial coordinate ( $z$ value), so when the balls are close to the inlet, the yield of the products is relatively big.

\subsection{Multi-layer and multi-circle balls}

For multi-layer and multi-circle model, the 2-circle and 3-circle multi-layer balls are studied. As an illustrative case, the model with 2-circle and 4-layer balls is schematically shown in Fig. 14, which is superposed by the single-layer balls with 2circle along $z$-axis. The balls near the fiber are defined as circle a and the other circle near the monolith is circle $\mathrm{b}$. The numbers of balls in circles $\mathrm{a}$ and $\mathrm{b}$ are 15 and 20 , and the radial distances are $0.65 \mathrm{~mm}$ and $0.93 \mathrm{~mm}$ respectively. The axial distance to the inlet of the first layer is $0.2 \mathrm{~mm}$, and then the axial spaces of every adjacent two layers are all set as $0.3 \mathrm{~mm}$.

The outlet $\mathrm{CH}_{3} \mathrm{OH}$ concentrations for the models with 2-circle and 3-circle multilayer balls are shown in Fig. 15. It can be observed that the outlet $\mathrm{CH}_{3} \mathrm{OH}$ average concentration increases with the layer number firstly and then decreases after 7 layers 
for 2-circle model, and 5 layers for 3-circle model. Although more layer number increases the surface area for photoreaction, the disturbance of the balls to the flow also gets strong. The promoting effect on the methanol formation is weak when the balls are far away from the entrance. As a result, 7 layers and 5 layers are preferred for better photocatalytic $\mathrm{CO}_{2}$ reduction in OFMR with 2-circle and 3-circle balls, as shown in Fig. 15. The $\mathrm{CH}_{3} \mathrm{OH}$ concentrations for the 2-circle and 7-layer balls model, 3-circle and 5layer balls model increases by $6.27 \%$ and $11.43 \%$ respectively, compared with the traditional OFMR without balls.

\section{Conclusions}

The photocatalytic carbon dioxide reduction in a novel optical fiber monolith reactor with transparent glass balls is proposed. For the model with single-circle and single-layer balls, the outlet methanol concentration increases with increasing the ball number. In general, the closer the distance from the balls to the fiber and the inlet is, the higher the methanol production is. The methanol concentration rises with increasing the circle and layer numbers. The methanol concentrations for the 2-circle and 7-layer balls model, 3-circle and 5-layer balls model increases by $6.27 \%$ and $11.43 \%$ respectively, compared with the traditional optical fiber monolith reactor without glass balls, so the 3-circle and 5-layer configuration is recommended.

The photocatalytic reduction performance of carbon dioxide is improved for the proposed optical fiber monolith reactor, which indicates a new direction to the development and innovation of carbon dioxide photo-hydrogenation. In future studies, new types of carbon dioxide photoreactor with various geometric structures will emerge 
in large numbers, which can effectively restrain greenhouse gas emission and mitigate energy shortage.

\section{Acknowledgments}

The financial supports for this research, from the National Natural Science Foundation of China (Grant No. 51776067) and the National Basic Research Program of China (Grant No. 2015CB251503), are gratefully acknowledged. The authors also thank the support provided by the Royal Society International Project of UK (IE150489). 


\section{Reference}

[1] Tahir M, Amin NS. Advances in visible light responsive titanium oxide-based photocatalysts for $\mathrm{CO}_{2}$ conversion to hydrocarbon fuels. Energy Convers Manag 2013;76:194-214.

[2] Yang MQ, Xu YJ. Photocatalytic conversion of $\mathrm{CO}_{2}$ over graphene-based composites: current status and future perspective. Nanoscale Horizons 2016;1:185-200.

[3] Delavari S, Amin NS. Photocatalytic conversion of $\mathrm{CO}_{2}$ and $\mathrm{CH}_{4}$ over immobilized titania nanoparticles coated on mesh: Optimization and kinetic study. Appl Energ 2016,162:1171-85.

[4] Wan KKW, Li DHW, Pan W, Lam JC. Impact of climate change on building energy use in different climate zones and mitigation and adaptation implications. Appl Energ 2012;97(3):274-82.

[5] Lo CC, Hung $\mathrm{CH}$, Yuan CS, Wu JF. Photoreduction of carbon dioxide with $\mathrm{H}_{2}$ and $\mathrm{H}_{2} \mathrm{O}$ over $\mathrm{TiO}_{2}$ and $\mathrm{ZrO}_{2}$ in a circulated photocatalytic reactor. Sol Energy Mater Sol Cells 2007;91:1765-74.

[6] Kočí K, Matějová L, Kozák O, Čapek L, Valeš V, Reli M, et al. ZnS/MMT nanocomposites: The effect of $\mathrm{ZnS}$ loading in MMT on the photocatalytic reduction of carbon dioxide. Appl Catal B Environ 2014;158-159:410-7.

[7] Castellani B, Gambelli AM, Morini E, et al. Experimental Investigation on $\mathrm{CO}_{2}$ Methanation Process for Solar Energy Storage Compared to $\mathrm{CO}_{2}$-Based Methanol Synthesis. Energies 2017;10(7):855. 
[8] Macdowell N, Florin N, Buchard A, et al. An overview of $\mathrm{CO}_{2}$ capture technologies. Energy Environ Sci 2010; 3(11):1645-69.

[9] Chu F, Liu Y, Yang L, Du X, Yang Y. Ammonia escape mass transfer and heat transfer characteristics of $\mathrm{CO}_{2}$ absorption in packed absorbing column. Appl Energ 2017;205:1596-604.

[10] Chu F, Yang L, Du X, Yang Y. $\mathrm{CO}_{2}$ capture using MEA (monoethanolamine) aqueous solution in coal-fired power plants: Modeling and optimization of the absorbing columns. Energy 2016;109:495-505.

[11] Chu F, Yang L, Du X, Yang Y. Mass transfer and energy consumption for $\mathrm{CO}_{2}$ absorption by ammonia solution in bubble column. Appl Energ 2017;190:106880.

[12] Castellani B, Morini E, Bonamente E, et al. Experimental investigation and energy considerations on hydrate-based biogas upgrading with $\mathrm{CO}_{2}$ valorization. Biomass \& Bioenergy 2017;105:364-72.

[13] Ola O, Maroto-Valer MM. $\mathrm{CO}_{2}$ Conversion into Valuable Fuels Using Chromium Based Supports. Energy Procedia 2014;63:7963-7.

[14] Wee JH. A review on carbon dioxide capture and storage technology using coal fly ash. Appl Energ 2013;106(11):143-51.

[15] Ramachandriya KD, Kundiyana DK, Wilkins MR, et al. Carbon dioxide conversion to fuels and chemicals using a hybrid green process. Appl Energ 2013; 112(4):289-99.

[16] Pérez-Fortes M, Schöneberger JC, Boulamanti A, et al. Methanol synthesis using 
captured $\mathrm{CO}_{2}$, as raw material: Techno-economic and environmental assessment. Appl Energ 2016;161:718-32.

[17] Reilly K, Wilkinson DP, Taghipour F. Photocatalytic water splitting in a fluidized bed system: Computational modeling and experimental studies. Appl Energ 2018; $222: 423-36$.

[18] Ola O, Maroto-Valer MM. Review of material design and reactor engineering on $\mathrm{TiO}_{2}$ photocatalysis for $\mathrm{CO}_{2}$ reduction. J Photochem Photobiol C Photochem Rev 2015;24:16-42.

[19] Puangpetch T, Chavadej S, Sreethawong T. Hydrogen production over Auloaded mesoporous-assembled $\mathrm{SrTiO}_{3}$ nanocrystal photocatalyst: Effects of molecular structure and chemical properties of hole scavengers. Energy Convers Manag 2011;52:2256-61.

[20] Yuan K, Yang L, Du X, Yang Y. Performance analysis of photocatalytic $\mathrm{CO}_{2}$ reduction in optical fiber monolith reactor with multiple inverse lights. Energy Convers Manag 2014;81:98-105.

[21] Chu F, Li S, Chen H, Yang L, Ola O, Maroto-Valer M, et al. Modeling photocatalytic conversion of carbon dioxide in bubbling twin reactor. Energy Convers Manag 2017;149:514-25.

[22] Cheng YH, Nguyen VH, Chan HY, Wu JCS, Wang WH. Photo-enhanced hydrogenation of $\mathrm{CO}_{2}$ to mimic photosynthesis by $\mathrm{CO}$ co-feed in a novel twin reactor. Appl Energ 2015;147:318-24.

[23] Wu JCS, Wu TH, Chu T, Huang H, Tsai D. Application of Optical-fiber 
Photoreactor for $\mathrm{CO}_{2}$ Photocatalytic Reduction. Top Catal 2008;47:131-6.

[24] Tahir M, Amin NS. Recycling of carbon dioxide to renewable fuels by photocatalysis: Prospects and challenges. Renew Sustain Energy Rev 2013;25:560-79.

[25] Xiong Z, Lei Z, Ma S, Chen X, Gong B, Zhao Y, et al. Photocatalytic $\mathrm{CO}_{2}$ reduction over $\mathrm{V}$ and $\mathrm{W}$ codoped $\mathrm{TiO}_{2}$ catalyst in an internal-illuminated honeycomb photoreactor under simulated sunlight irradiation. Appl Catal B Environ 2017;219:412-24.

[26] Lin H, Valsaraj KT. An optical fiber monolith reactor for photocatalytic wastewater treatment. AIChE J 2006;52:2271-80.

[27] Wu JCS, Lin HM, Lai CL. Photo reduction of $\mathrm{CO}_{2}$ to methanol using opticalfiber photoreactor. Appl Catal A Gen 2005;296:194-200.

[28] Liou PY, Chen SC, Wu JCS, Liu D, Mackintosh S, Maroto-Valer M, et al. Photocatalytic $\mathrm{CO}_{2}$ reduction using an internally illuminated monolith photoreactor. Energy Environ Sci 2011;4:1487-94.

[29] Wang T, Yang L, Du X, Yang Y. Numerical investigation on $\mathrm{CO}_{2}$ photocatalytic reduction in optical fiber monolith reactor. Energy Convers Manag 2013;65:299-307.

[30] Boyjoo Y, Ang M, Pareek V. Light intensity distribution in multi-lamp photocatalytic reactors. Chem Eng Sci 2013;93:11-21.

[31] Wang ZY, Chou HC, Wu JCS, Tsai DP, Mul G. $\mathrm{CO}_{2}$ photoreduction using $\mathrm{NiO} / \mathrm{InTaO}_{4}$ in optical-fiber reactor for renewable energy. Appl Catal A Gen 
2010;380:172-7.

[32] Rathore MM, Kapuno R. Engineering Heat Transfer, Second Edition[M]. Jones and Bartlett Publishers, Inc. 2010.

[33] Tahir M, Amin NS. Photocatalytic $\mathrm{CO}_{2}$ reduction and kinetic study over $\mathrm{In} / \mathrm{TiO}_{2}$ nanoparticles supported microchannel monolith photoreactor. Appl Catal A Gen 2013;467:483-96.

[34] Denny F, Scott J, Peng GD, Amal R. Channelled optical fibre photoreactor for improved air quality control. Chem Eng Sci 2010;65:882-9.

[35] Harriott P. Chemical reactor design. Marcel Dekker; 2003.

[36] Marinangeli RE, Ollis DF. Photoassisted heterogeneous catalysis with optical fibers: I. Isolated single fiber. AIChE J 1977;23:415-26.

[37] Peill NJ, Hoffmann MR. Development and Optimization of a $\mathrm{TiO}_{2}$-Coated FiberOptic Cable Reactor: Photocatalytic Degradation of 4-Chlorophenol. Environ Sci Technol 1995; 29(12):2974.

[38] Choi W, Ko JY, Park H, Chung JS. Investigation on $\mathrm{TiO}_{2}$-coated optical fibers for gas-phase photocatalytic oxidation of acetone. Appl Catal B Environ 2001;31:209-20.

[39] Puma GL, Yue PL. A laminar falling film slurry photocatalytic reactor. Part Imodel development. Chem Eng Sci 1998;53:2993-3006. 


\section{Graphical abstract}
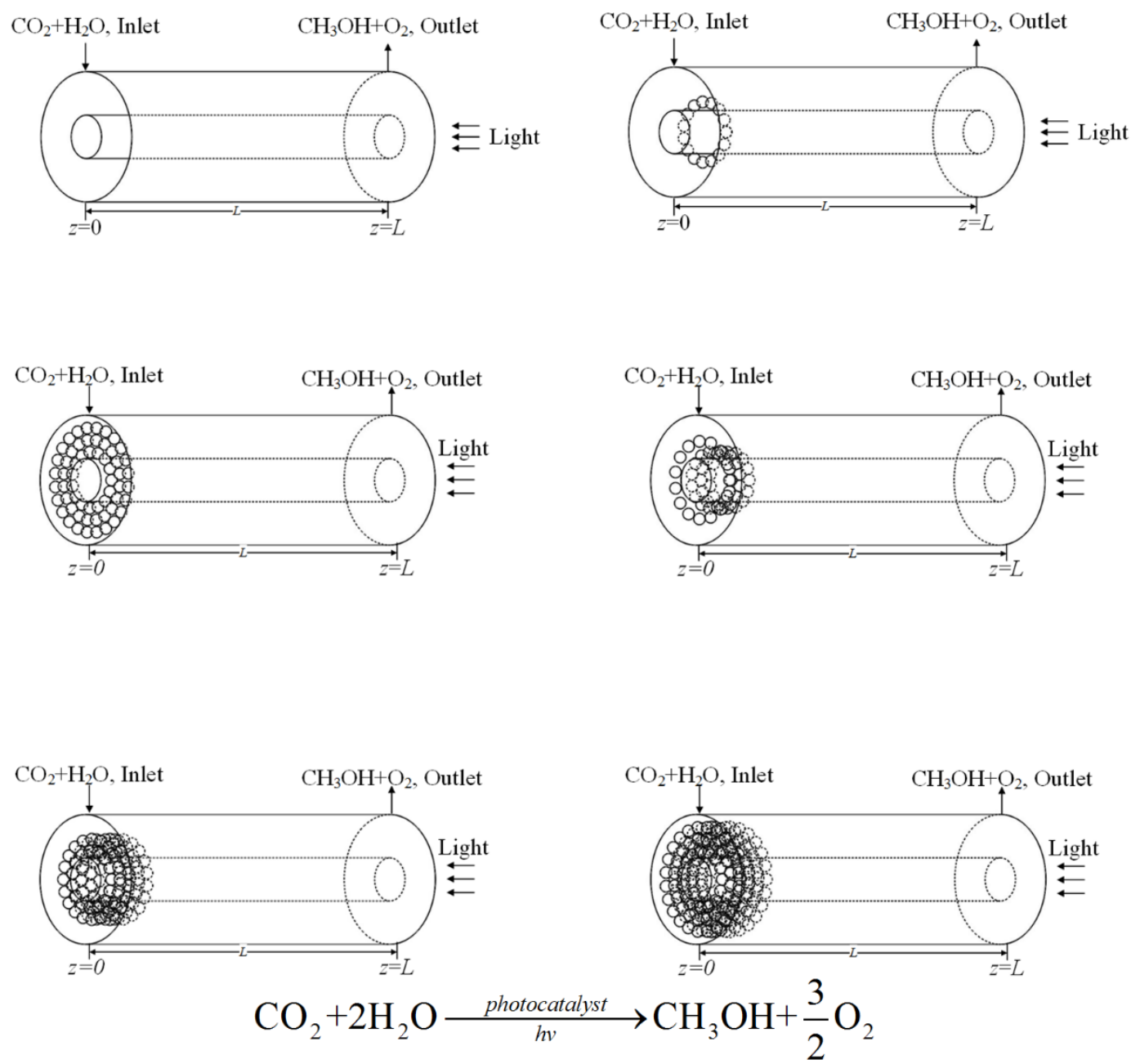
Table 1

The parameters of the proposed model.

\begin{tabular}{|c|c|c|c|}
\hline Type & Variables & Values & Unit \\
\hline \multirow[t]{8}{*}{ Geometry } & $d_{f}$ & 1 & $\mathrm{~mm}$ \\
\hline & $R_{m}$ & 1.5 & $\mathrm{~mm}$ \\
\hline & $R_{f}$ & 0.5 & $\mathrm{~mm}$ \\
\hline & $V_{g s}$ & 0.01 & $\mathrm{~mm}^{3}$ \\
\hline & $D_{g s}$ & 0.2673 & $\mathrm{~mm}$ \\
\hline & $R_{g s}$ & 0.13365 & $\mathrm{~mm}$ \\
\hline & $L$ & 10 & $\mathrm{~mm}$ \\
\hline & $\delta$ & 400 & $\mathrm{~nm}$ \\
\hline Fluid dynamics & $V_{\text {inlet }}$ & 0.03 & $\mathrm{~mm} \mathrm{~s}^{-1}$ \\
\hline \multirow[t]{3}{*}{ Mass transfer } & $\mathrm{D}_{-} \mathrm{H}_{2} \mathrm{O}$ & $1.7327 \mathrm{E}-7$ & $\mathrm{~m}^{2} \mathrm{~s}^{-1}$ \\
\hline & $\mathrm{D}_{-} \mathrm{CH}_{3} \mathrm{OH}$ & $1.31 \mathrm{E}-7$ & $\mathrm{~m}^{2} \mathrm{~s}^{-1}$ \\
\hline & $\mathrm{D}_{-} \mathrm{O}_{2}$ & $1.31 \mathrm{E}-7$ & $\mathrm{~m}^{2} \mathrm{~s}^{-1}$ \\
\hline \multirow[t]{4}{*}{ Radiation field } & $\alpha$ & 0.386 & $\mathrm{~cm}^{-1}$ \\
\hline & $f_{\theta}$ & 0.762 & Dimensionless \\
\hline & $\beta$ & 1.95 & $\mathrm{~cm}^{-1}$ \\
\hline & $\varepsilon$ & 0.00102 & $\mathrm{~nm}^{-1}$ \\
\hline Kinetics & $k_{T}$ & $1.17 \mathrm{E}-10$ & $\mathrm{~m}^{4} \mathrm{~s}^{-1} \mathrm{~mol}^{-2}$ \\
\hline UV input & $I_{\text {input }}$ & 424.6 & $\mathrm{~W} \mathrm{~m} \mathrm{~m}^{-2}$ \\
\hline Inlet concentration & $C_{i, \mathrm{CO} 2}$ & 43.75 & $\mathrm{~mol} \mathrm{~m}^{-3}$ \\
\hline
\end{tabular}


$\mathrm{mol} \mathrm{m}^{-3}$ 
Fig. 1. Schematics of traditional and proposed OFMRs for one single channel. (a) Traditional, (b) proposed.

Fig. 2. Geometric structure of the proposed model.

Fig. 3. Methanol concentration and reaction rate in the photoreactor with 15 balls.

Fig. 4. Methanol concentration distribution in the photoreactor (unit in $\mathrm{mol} / \mathrm{m}^{3}$ ). (a) Traditional model, (b) proposed model.

Fig. 5. Average methanol concentrations along $z$-axis in traditional model and proposed model with 15 balls.

Fig. 6. Fluid velocity distribution in the photoreactor (unit in $\mathrm{m} / \mathrm{s}$ ). (a) Traditional, (b) proposed.

Fig. 7. Schematics of the photoreactors with different ball numbers.

Fig. 8. Outlet average methanol concentration at different ball numbers and axial coordinates $z_{g s}$.

Fig. 9. Outlet average methanol concentration at various $z_{g s}$ and $r_{g s}$.

Fig. 10. Schematics of the multi-layer balls model.

Fig. 11. Outlet methanol average concentration for multi-layer balls model.

Fig. 12. Schematics of the multi-circle balls model.

Fig. 13. Methanol concentration for multi-circle balls model.

Fig. 14. Schematics of the 2-circle and 4-layer balls model.

Fig. 15. Outlet methanol concentration for 2-circle and 3-circle multi-layer balls model. 

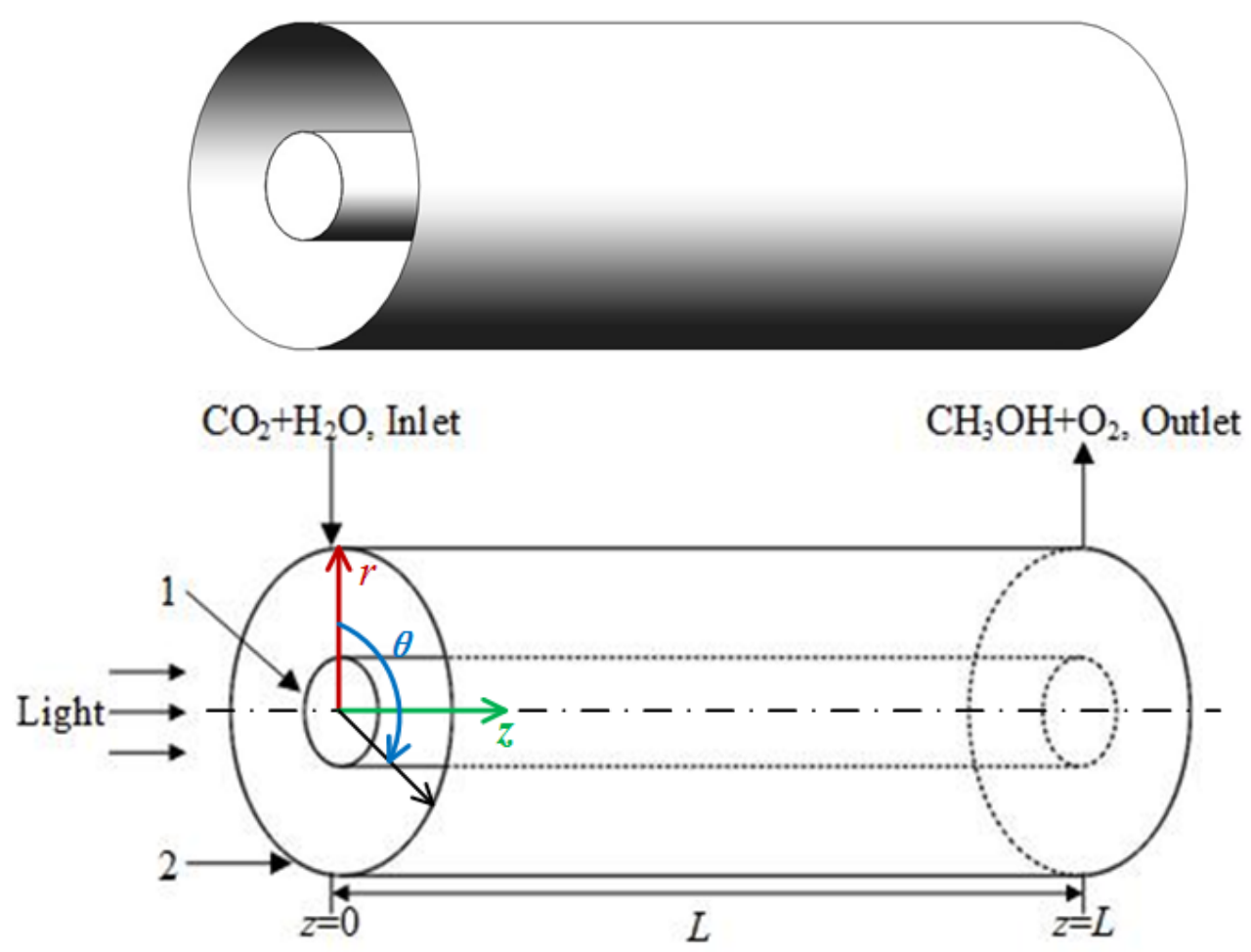

(a)
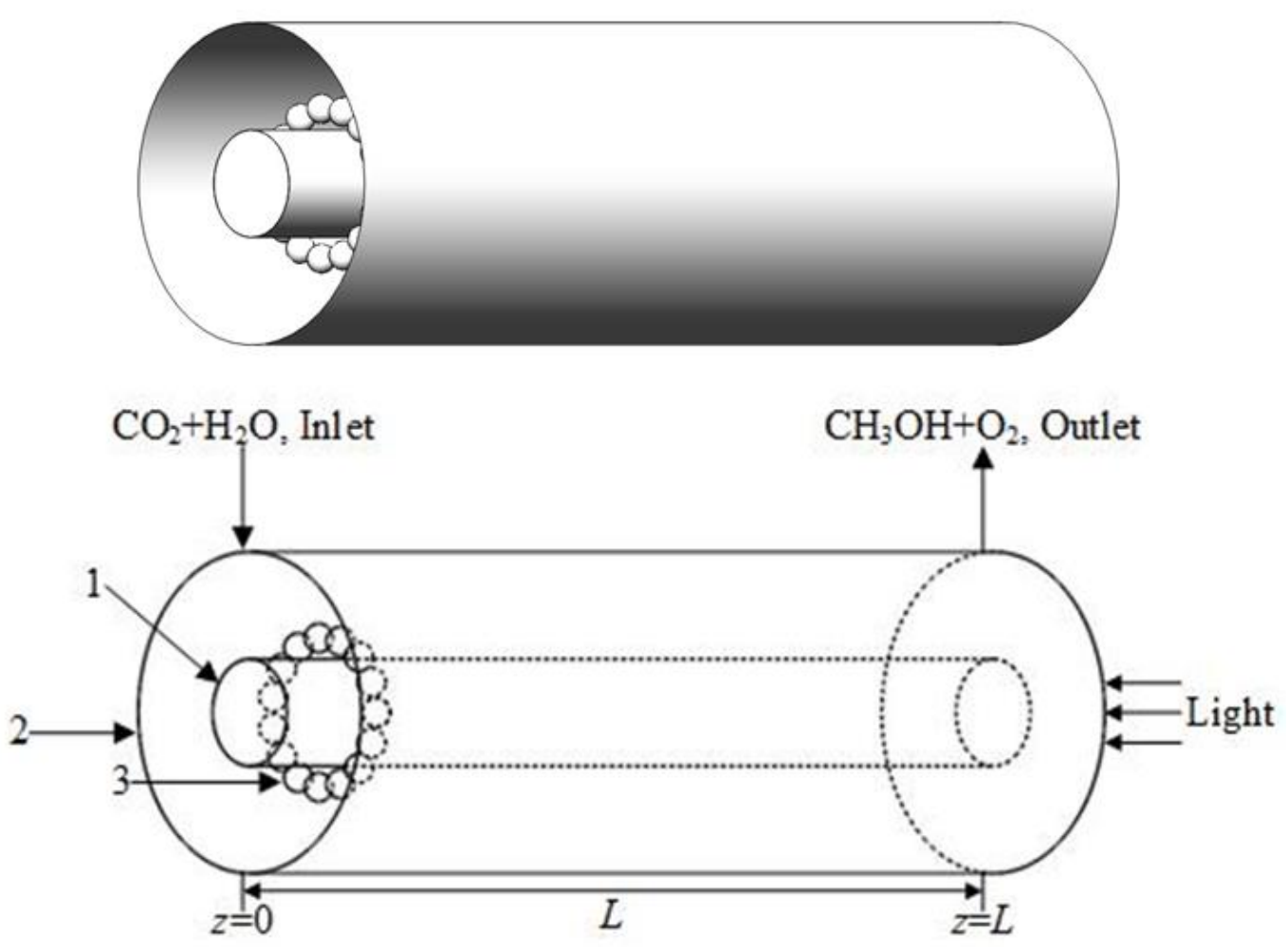

(b)

Fig. 1. 

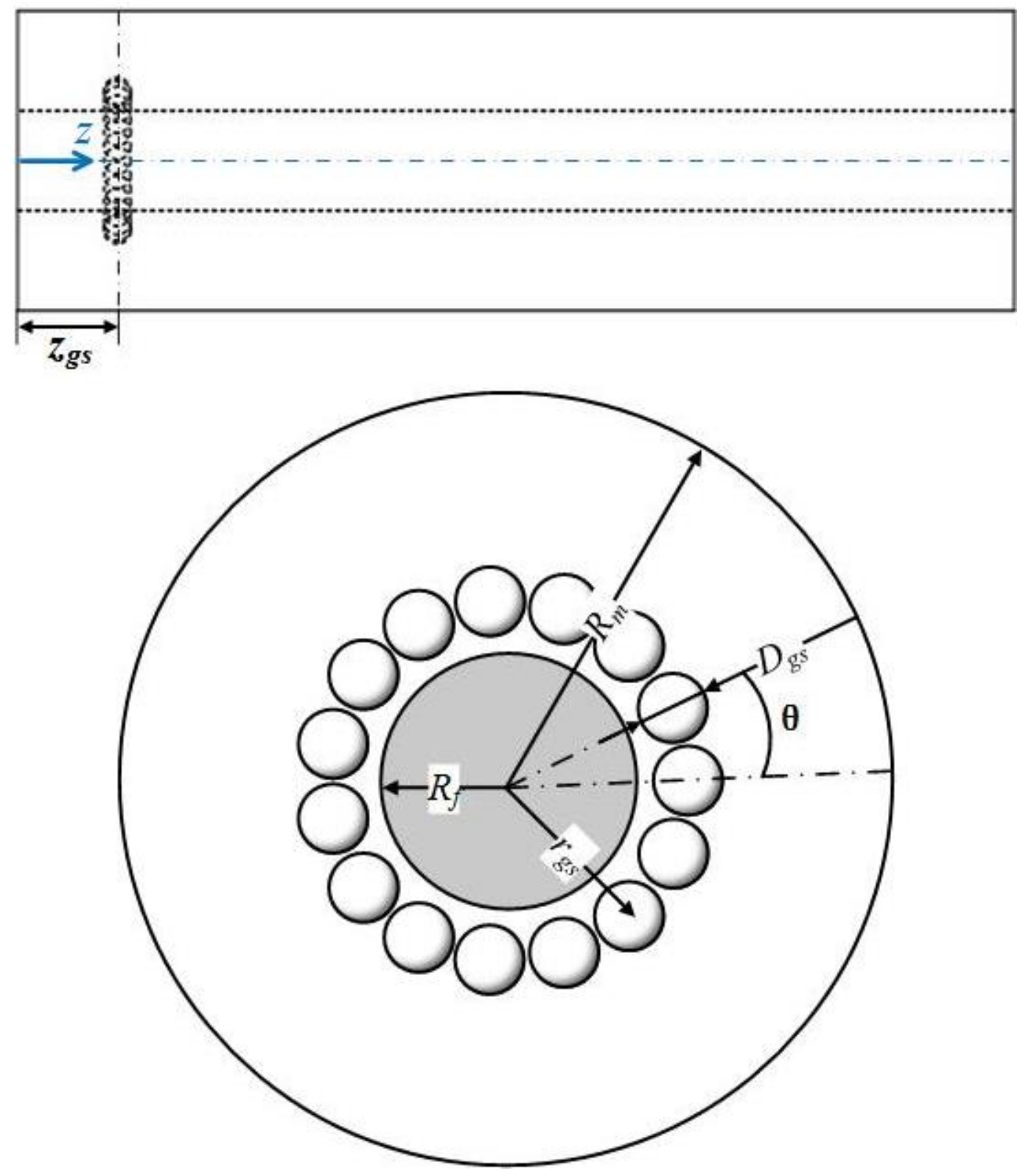

Fig. 2. 


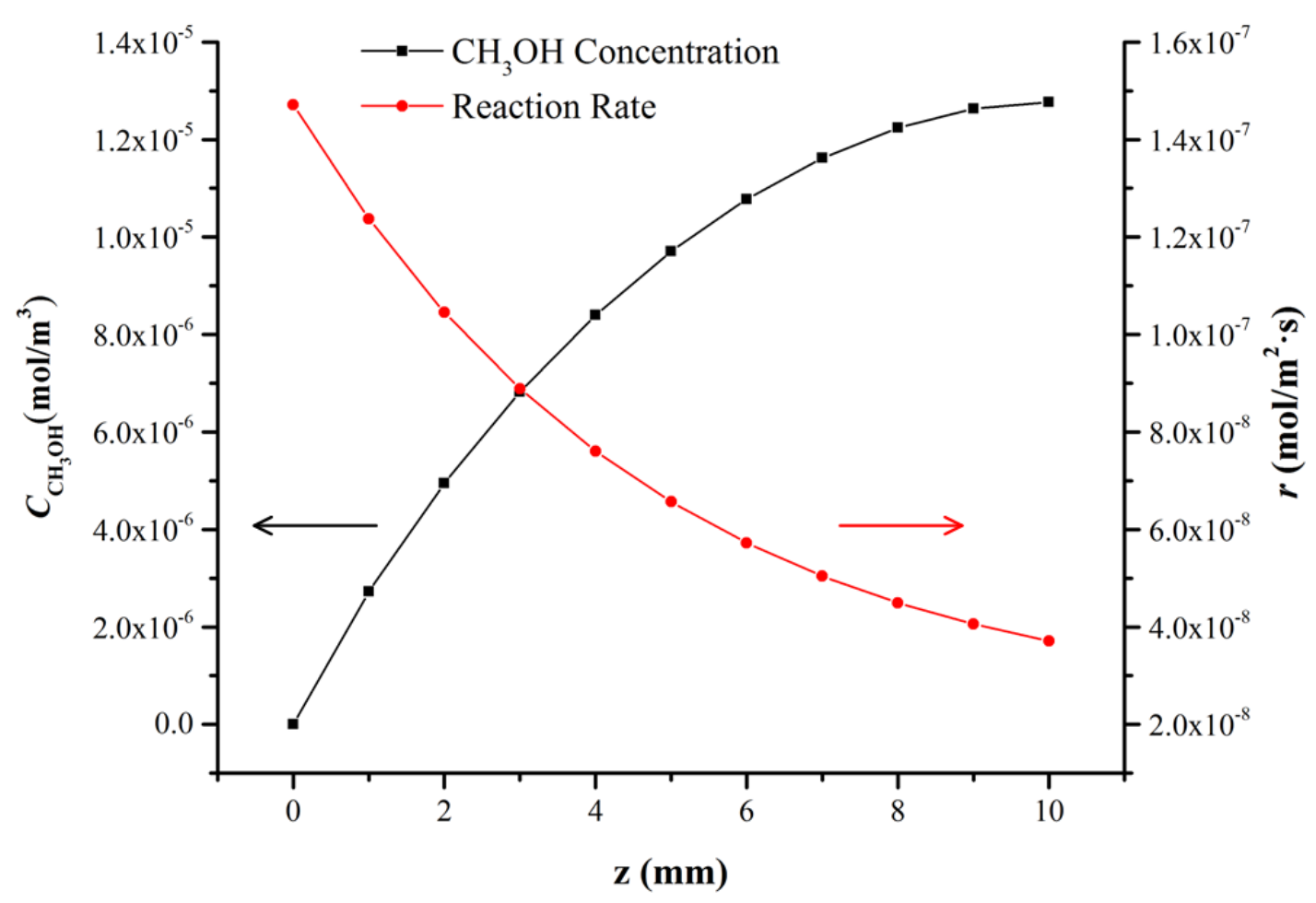

Fig. 3. 


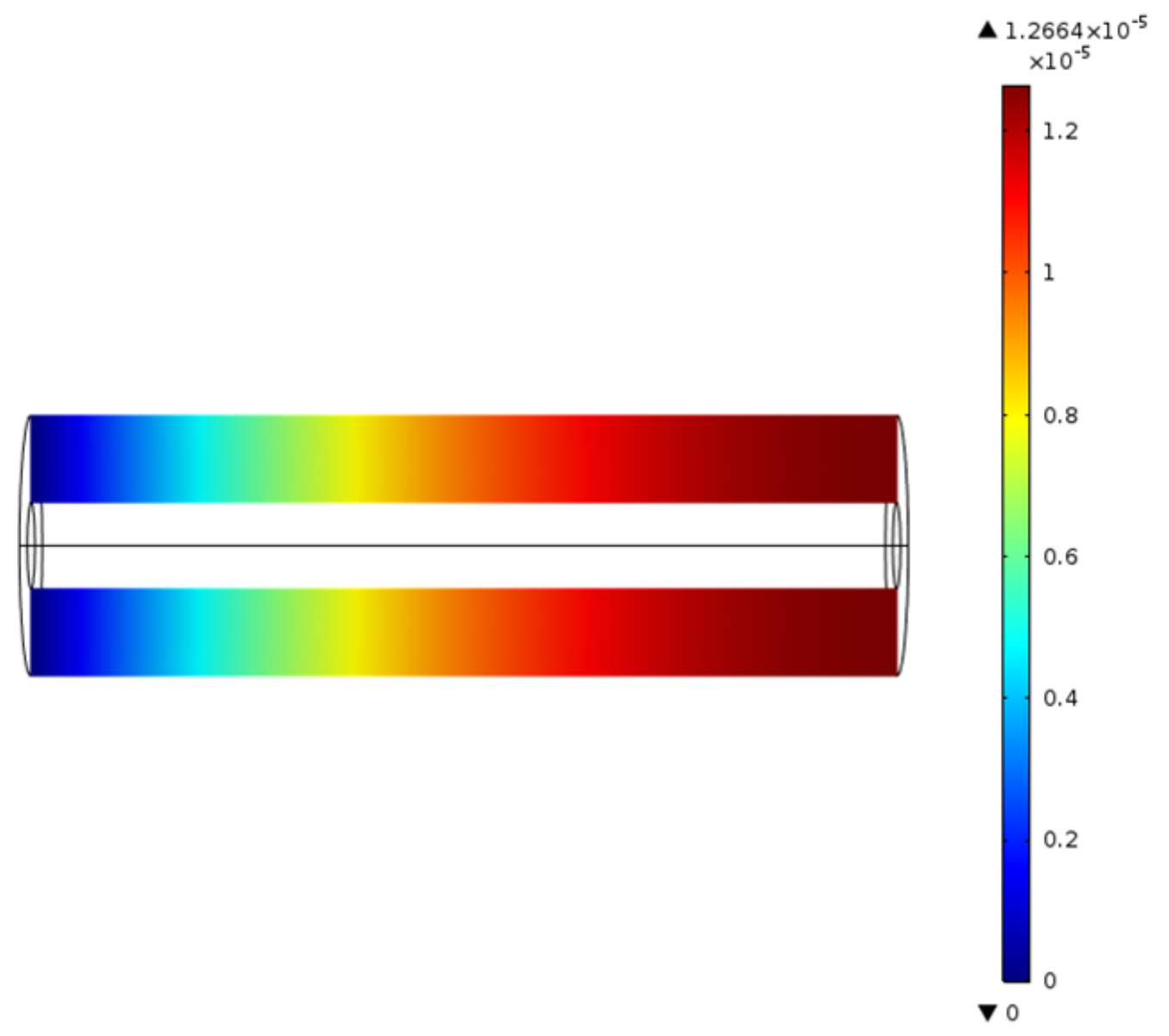

(a) 


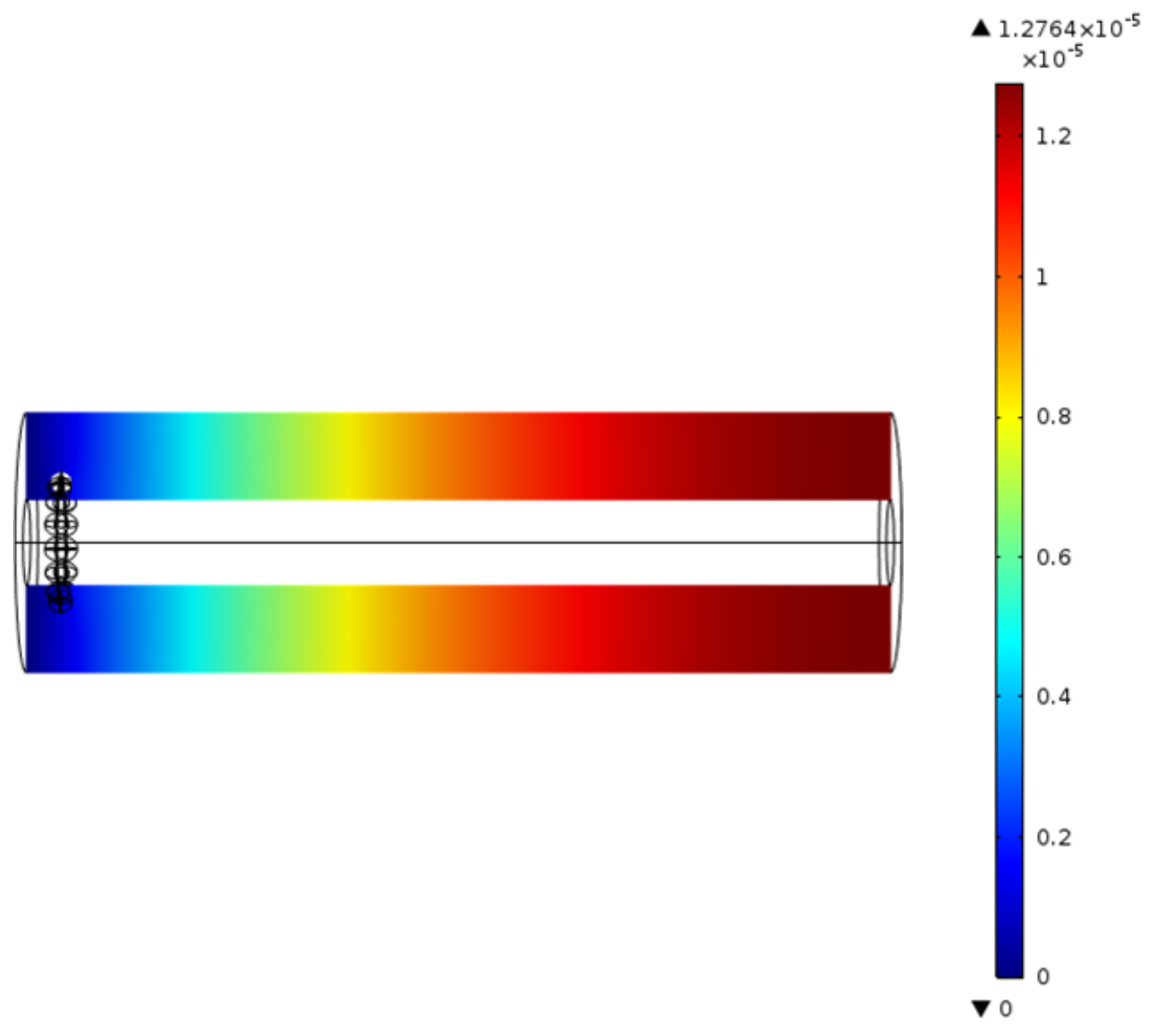

(b)

Fig. 4. 


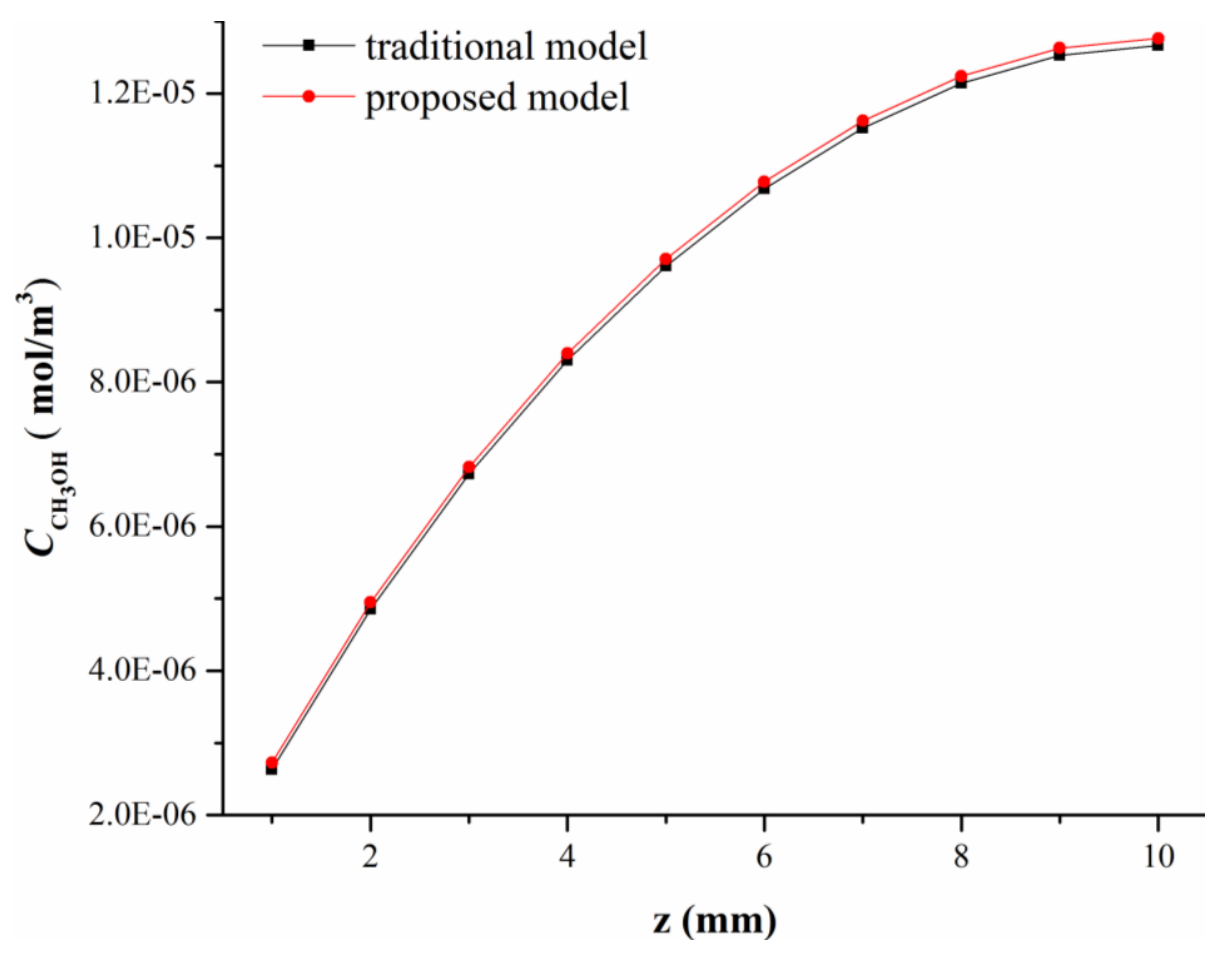

Fig. 5. 


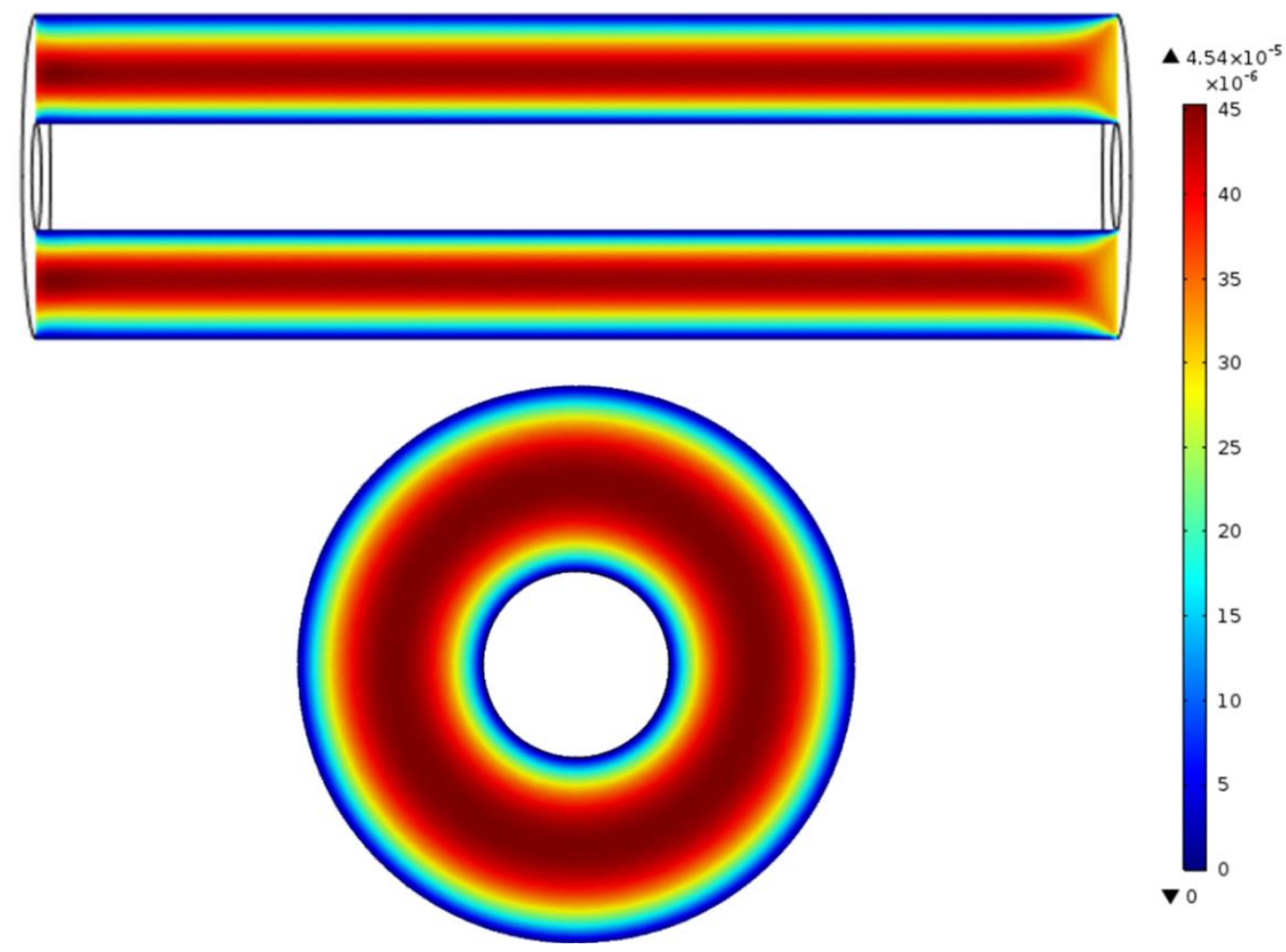

(a)

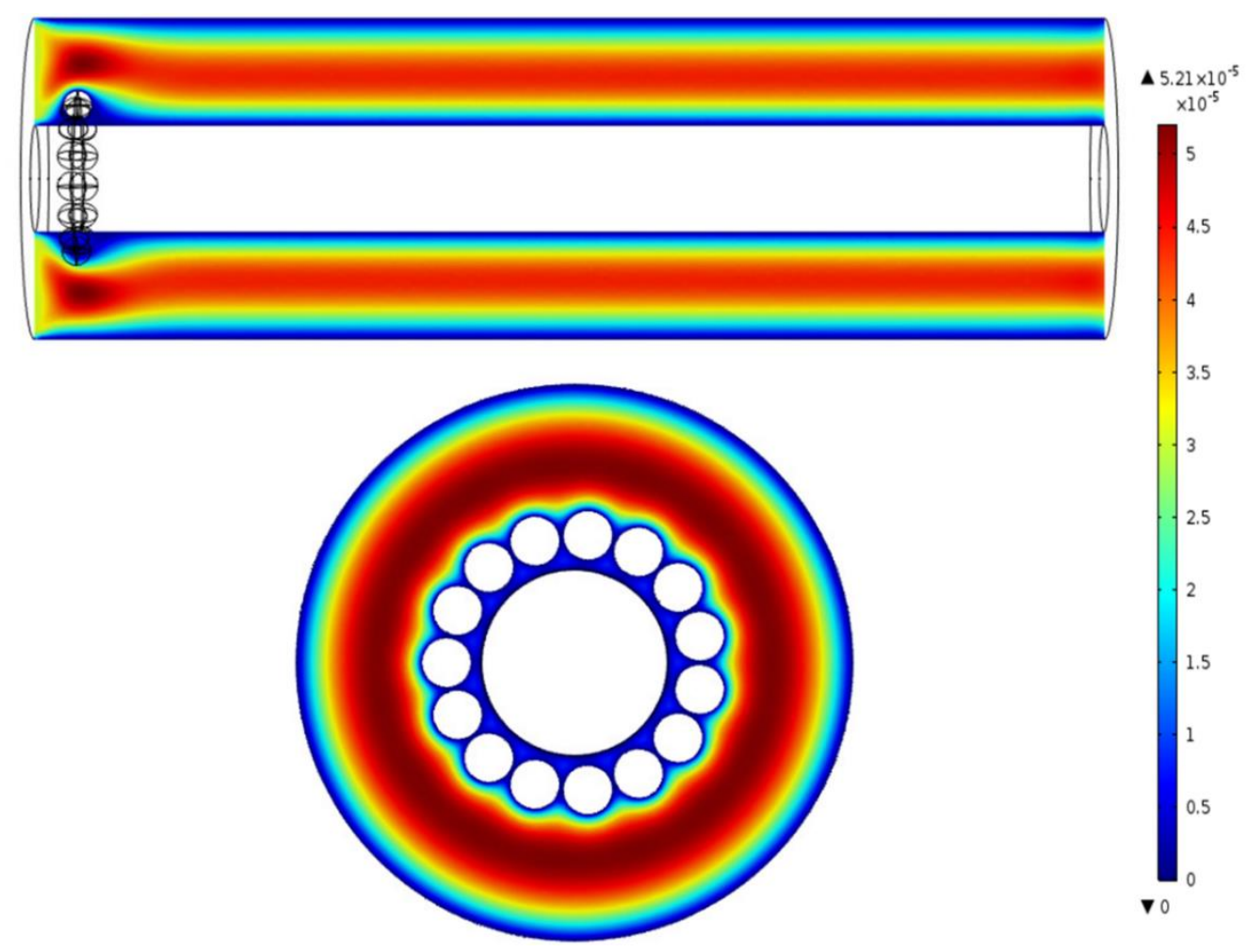

(b)

Fig. 6. 

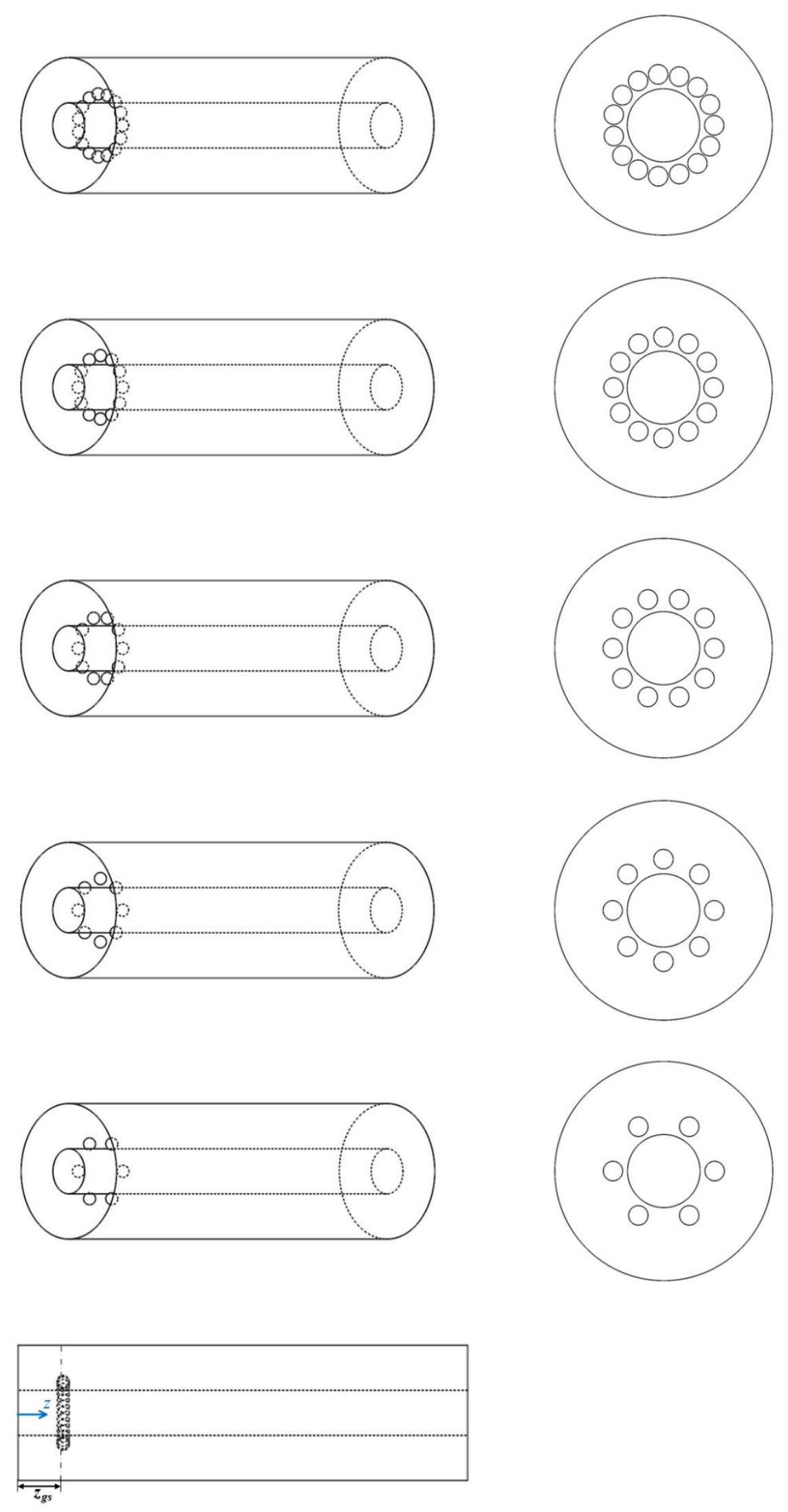

Fig. 7. 


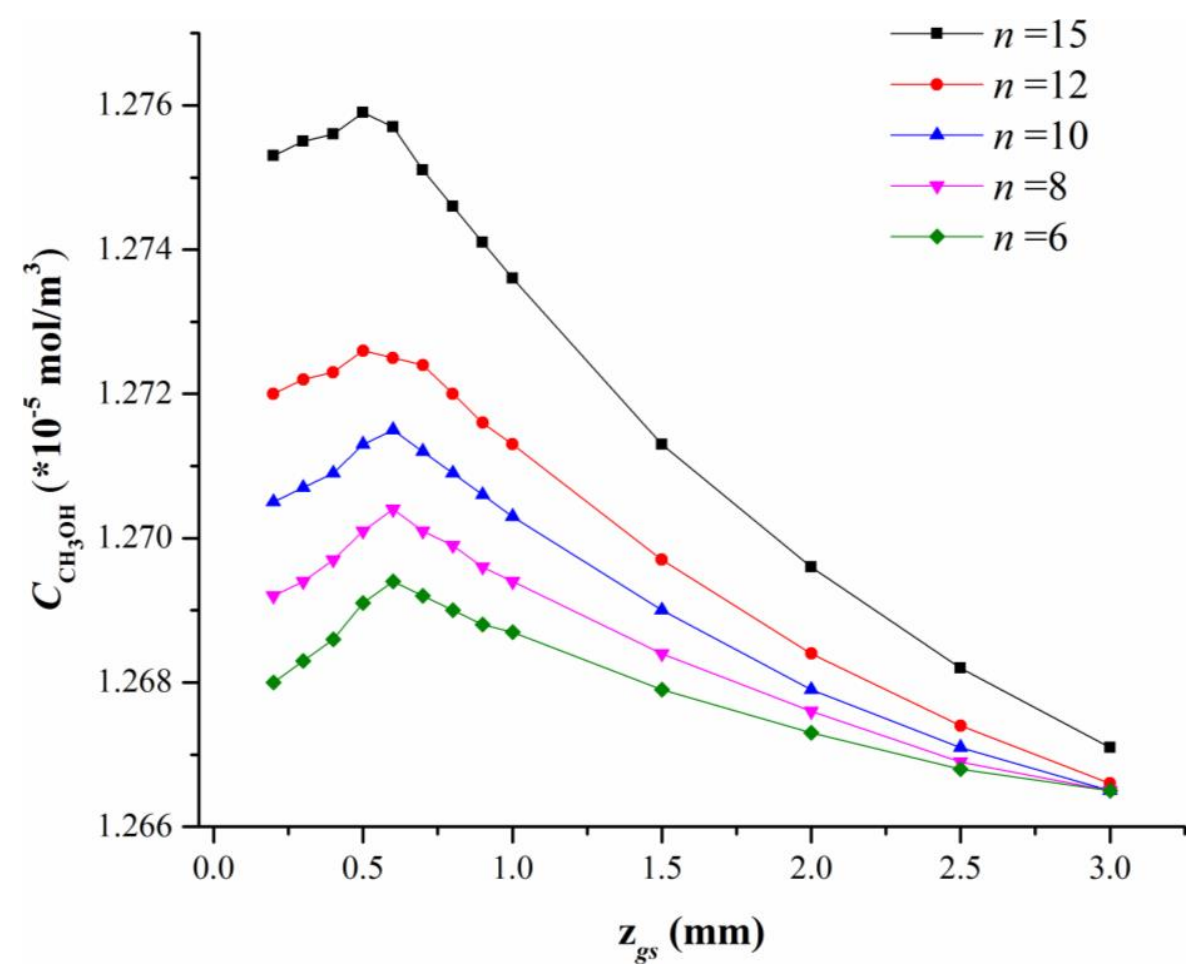

Fig. 8. 


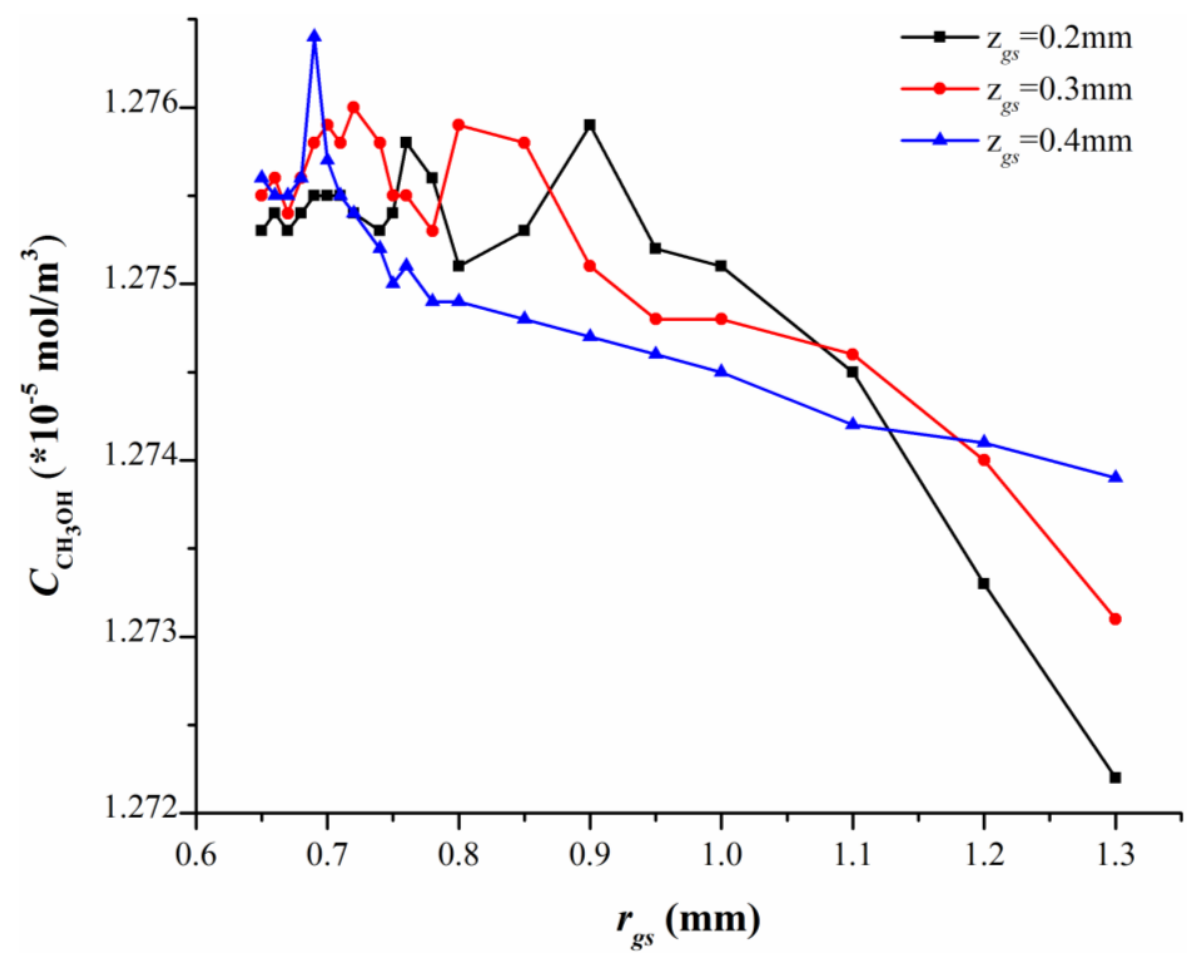

(a)

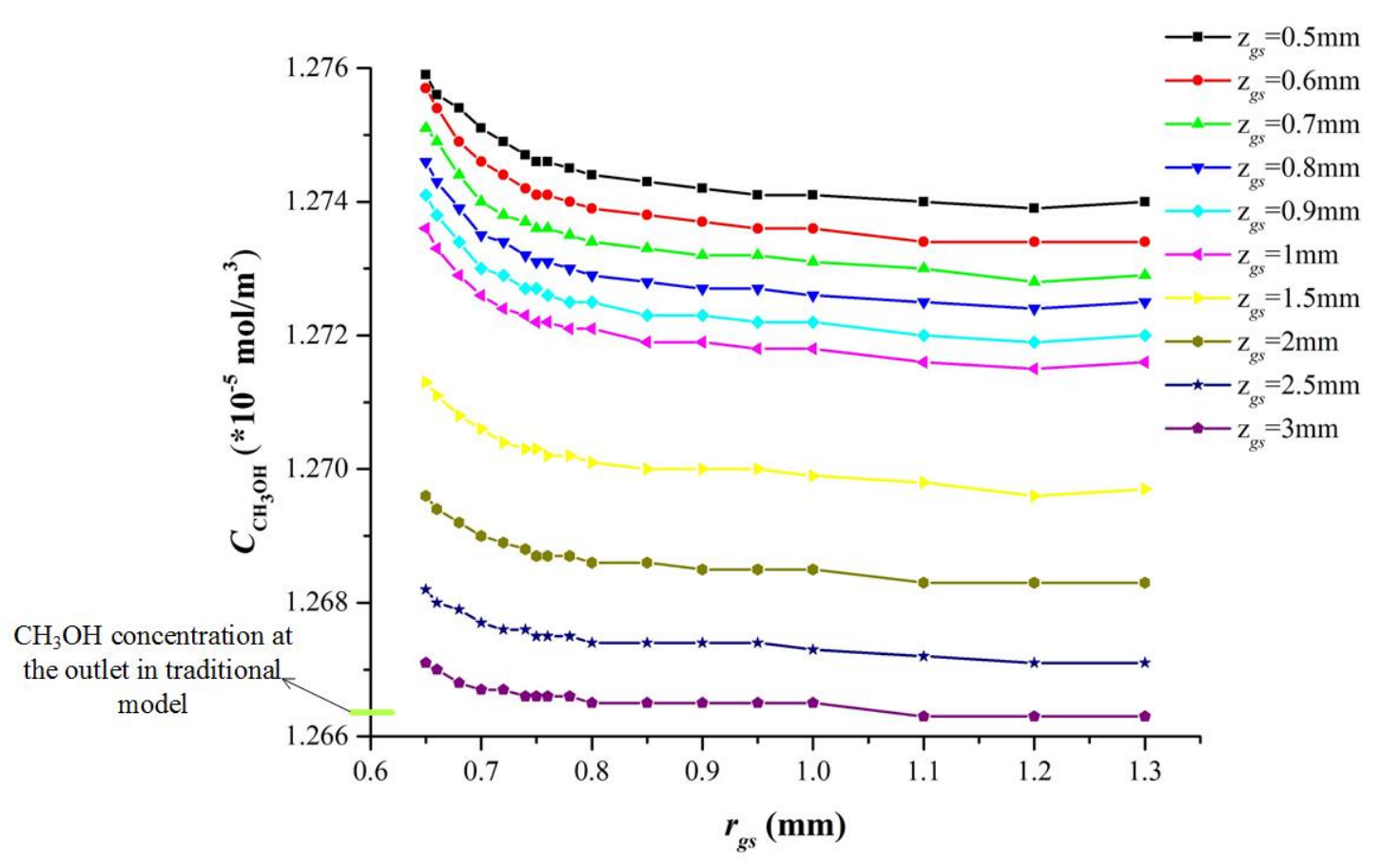

(b)

Fig. 9. 

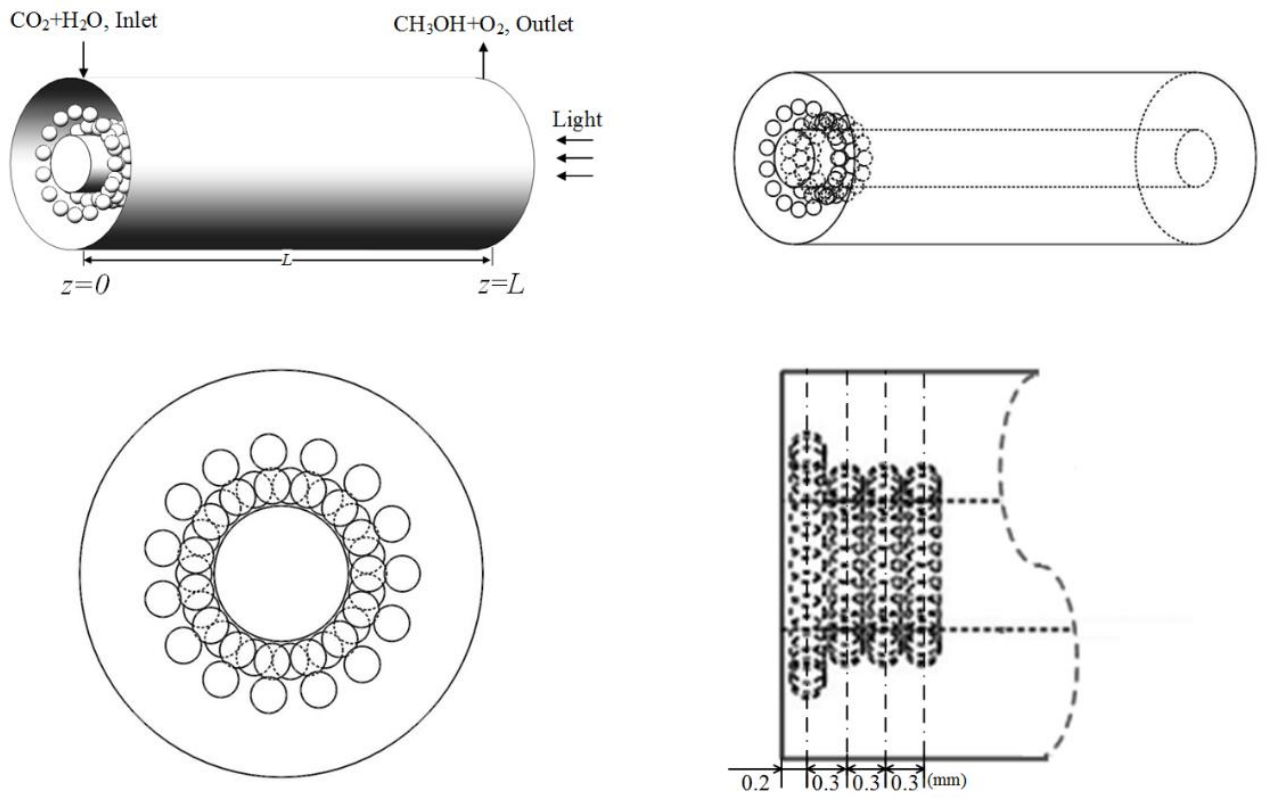

Fig. 10 . 


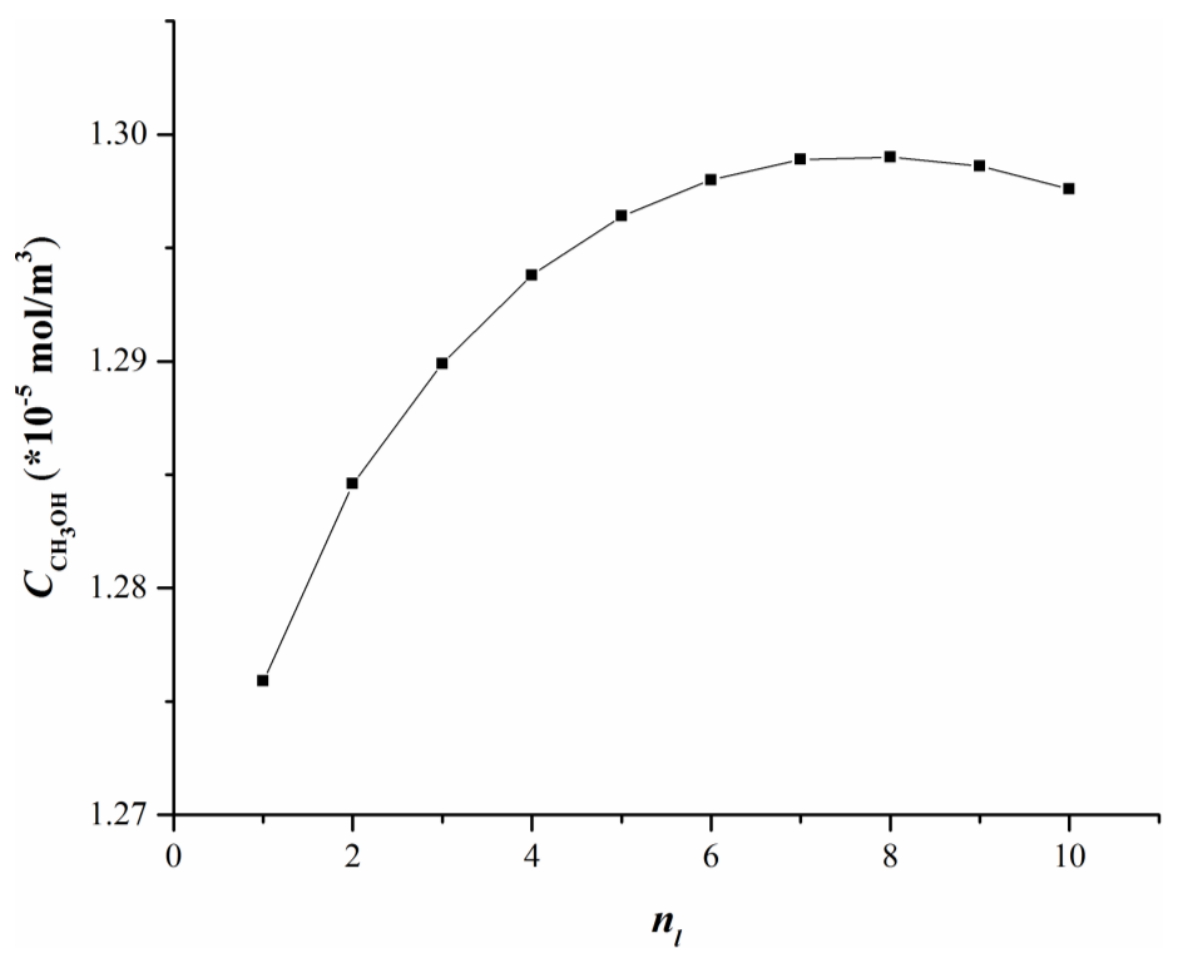

Fig. 11. 

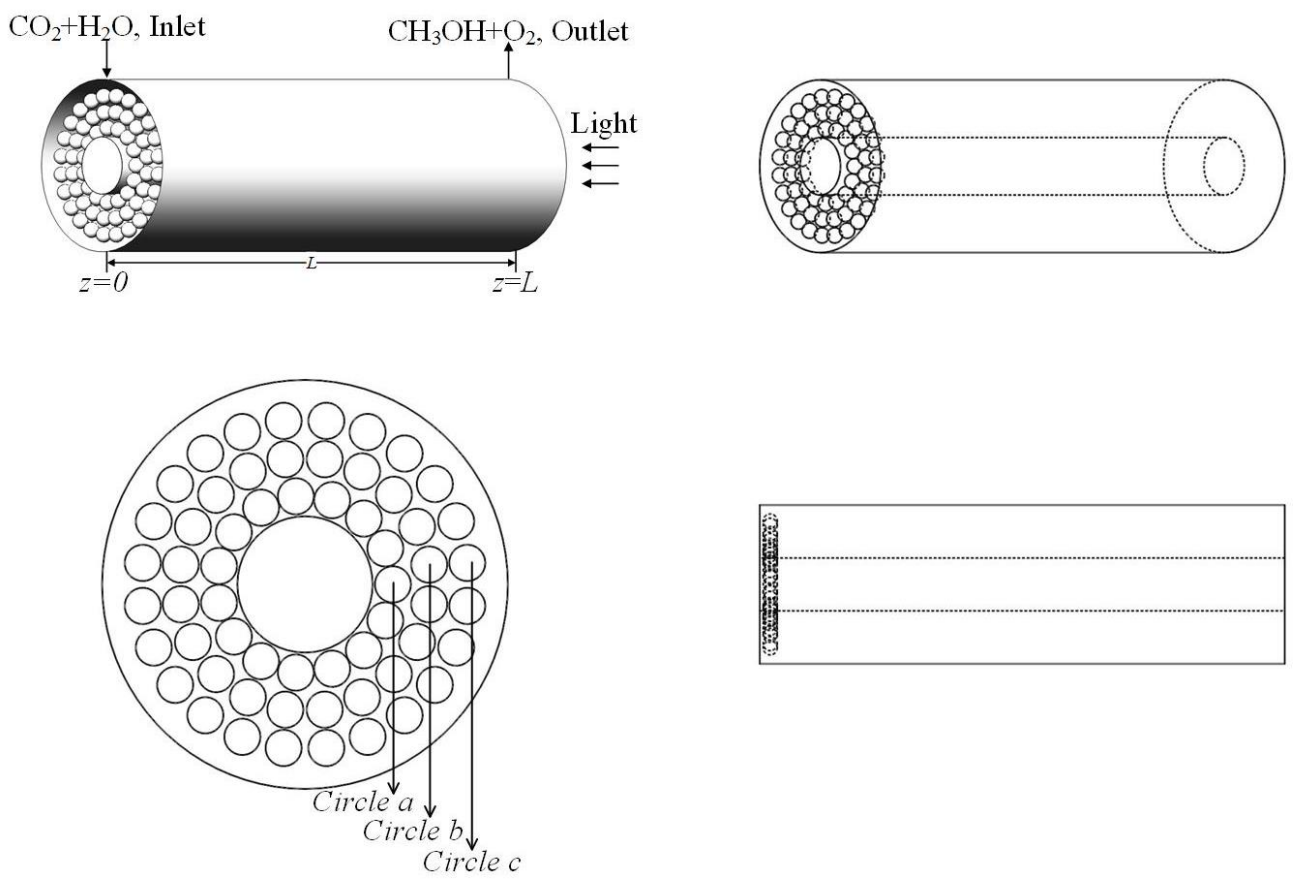

Fig. 12. 


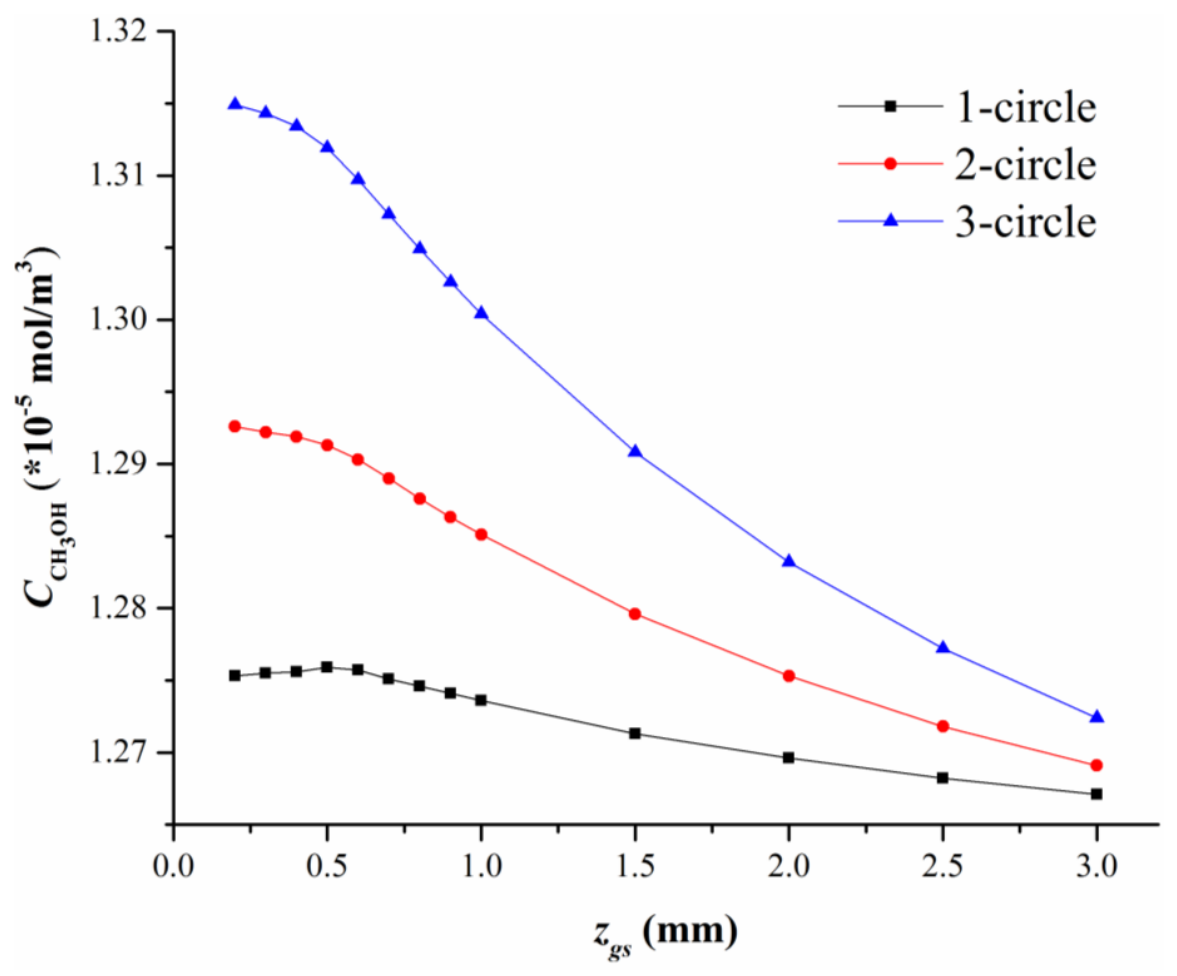

Fig. 13. 

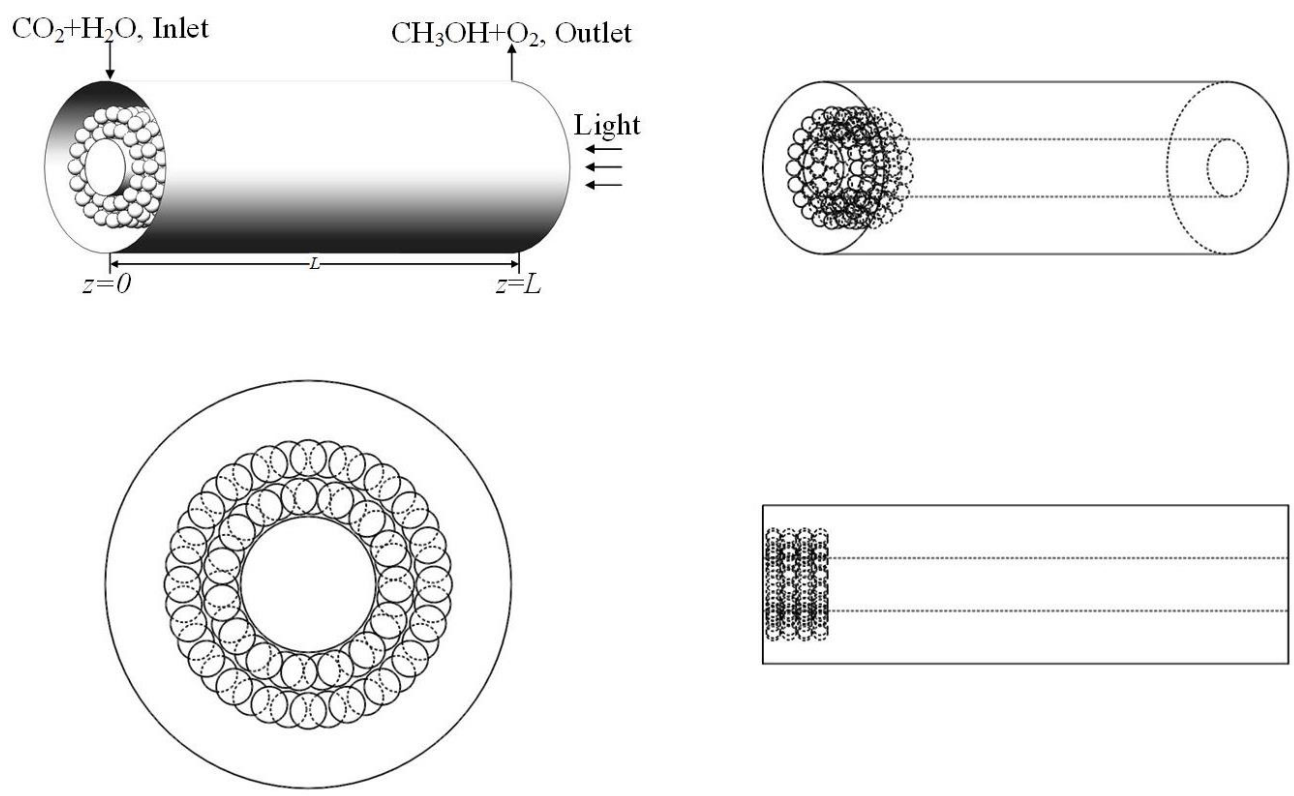

Fig. 14. 


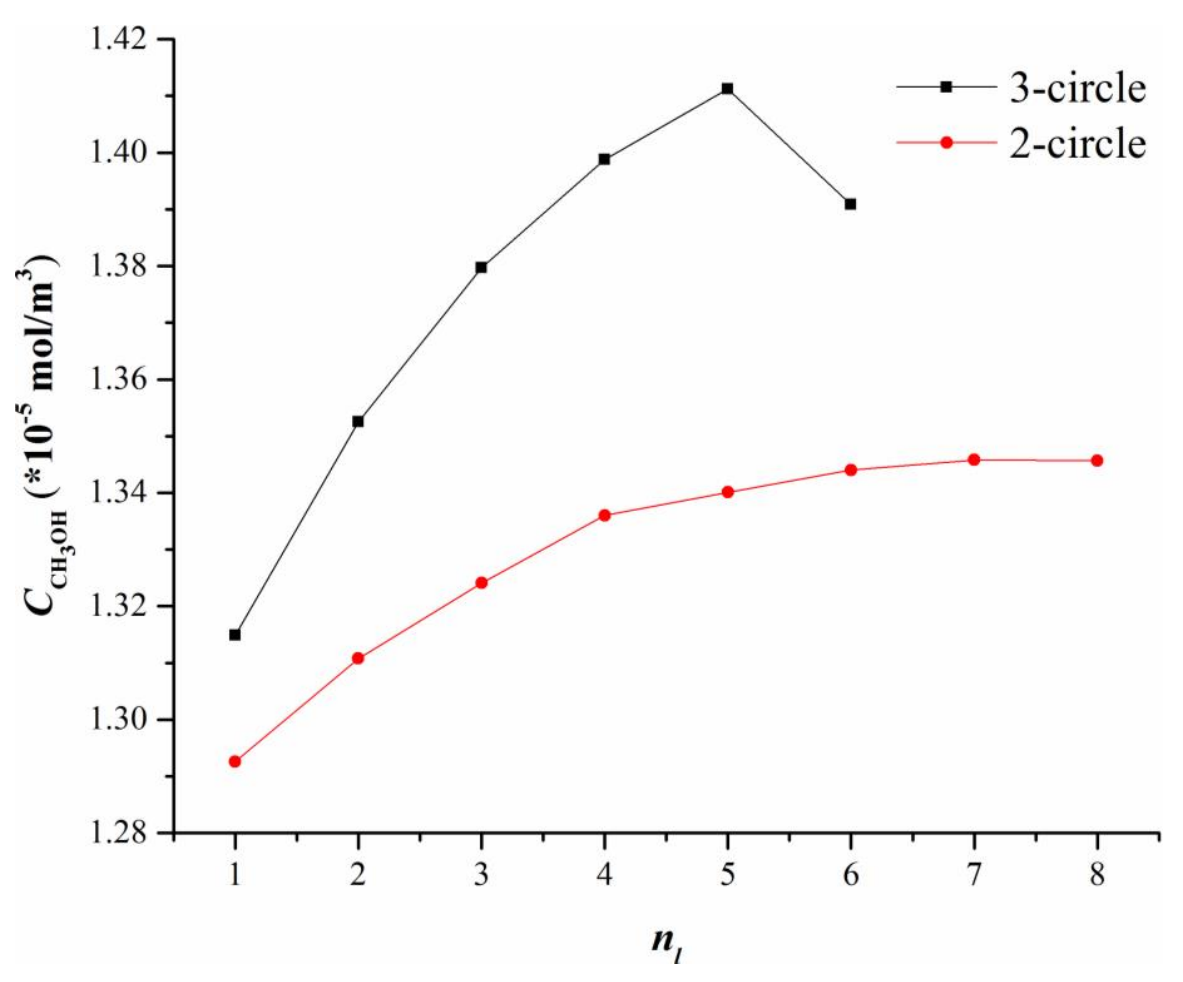

Fig. 15. 